\title{
A computational tool integrating host immunity with antibiotic dynamics to study tuberculosis treatment
}

Elsje Pienaarr,2, Nicholas A. Cilfone ${ }^{1}$, Philana Ling Lin³ ${ }^{3}$ Véronique Dartois ${ }^{4}$, Joshua T. Mattila5, Russ Butler6, JoAnne L. Flynn5, Denise E. Kirschner2,\# and Jennifer J. Linderman ${ }^{1, \#}$

${ }^{1}$ Department of Chemical Engineering, University of Michigan, Ann Arbor, Michigan, USA, ${ }^{2}$ Department of Microbiology and Immunology, University of Michigan Medical School, Ann Arbor, Michigan, USA, 3Department of Pediatrics, Children's Hospital of Pittsburgh of the University of Pittsburgh Medical Center, Pittsburgh, Pennsylvania, USA, ${ }^{4}$ Public Health Research Institute and New Jersey Medical School, Rutgers, The State University of New Jersey, Newark, New Jersey, USA, ${ }^{5}$ Department of Microbiology and Molecular Genetics, University of Pittsburgh, Pittsburgh, Pennsylvania, USA, ${ }^{6}$ Department of Health and Biomedical Sciences, Adventist University of Health Sciences, Orlando, Florida, USA.

\#: Corresponding authors: D.E. Kirschner: kirschne@umich.edu; J.J. Linderman: linderma@umich.edu.

Running title: Computational model of tuberculosis treatment 
Keywords: Pharmacodynamics, Pharmacokinetics, Agent based model, granuloma, Non-human primate, Rabbit, Isoniazid, Rifampicin, Antibiotic gradients, Suboptimal exposure.

\begin{abstract}
While active tuberculosis (TB) is a treatable disease, many complex factors prevent its global elimination. Part of the difficulty in developing optimal therapies is the large design space of antibiotic doses, regimens and combinations. Computational models that capture the spatial and temporal dynamics of antibiotics at the site of infection can aid in reducing the design space of costly and time-consuming animal pre-clinical and human clinical trials. The site of infection in TB is the granuloma, a collection of immune cells and bacteria that form in the lung, and new data suggest that penetration of drugs throughout granulomas is problematic. Here we integrate our computational model of granuloma formation and function with models for plasma pharmacokinetics, lung tissue pharmacokinetics and pharmacodynamics for two first line anti-TB antibiotics. The integrated model is calibrated to animal data. We make four predictions. First, antibiotics are frequently below effective concentrations inside granulomas, leading to bacterial growth between doses and contributing to the long treatment periods required for TB. Second, antibiotic concentration gradients form within granulomas, with lower concentrations toward their centers. Third, during antibiotic treatment, bacterial subpopulations shift from mostly intracellular to mostly extracellular. These extracellular bacteria are located in areas non-permissive for replication (hypoxic areas), presenting a changing
\end{abstract}


target population over time. Finally, we find that on an individual granuloma basis,

pre-treatment infection severity (including bacterial burden, host cell activation and host cell death) is predictive of treatment outcome.

\section{Introduction}

Despite the availability of antibiotics, active tuberculosis (TB) disease remains a global health concern[1]. TB is caused by infection with Mycobacterium tuberculosis (Mtb) leading to 8.6 million new cases reported in 2012[2]. Worldwide, TB has an $87 \%$ treatment success rate in new cases, leaving more than 1 million patients without cure[2].

The complex nature of the sites of infection, namely lung granulomas, complicates treatment. Granulomas are highly organized and dynamic immunological structures that develop in response to Mtb infection. Multiple granulomas (of various sizes, types, and bacterial burdens) are often present in a single patient, and these granulomas evolve independently of each other over time $[3,4]$. Therefore, it is important to understand antibiotic dynamics at the single granuloma level. Granulomas can be classified as caseous (acellular necrotic centers surrounded by macrophages and lymphocyte-rich cuffs), solid cellular (no necrotic cores with densely packed macrophages and T cells[5-7] or fibrotic (healing and long-term granulomas)[8]. Granulomas are heterogeneous structures, with different microenvironments (e.g. hypoxic caseous necrotic regions, macrophage-rich areas, lymphocytic cuff)[9] and bacterial subpopulations (e.g. replicating and nonreplicating)[10] developing within. This structural, spatial and bacterial 
heterogeneity in granulomas may present a significant obstacle for effective treatment.

Antibiotic dynamics, bacterial killing and host dynamics within granulomas during treatment remain largely undescribed and are challenging to evaluate in vivo[11]. Lung antibiotic concentrations, occasionally measured since the 1950s[1214], have recently been revisited using modern mass spectrometry-based techniques that allow visualization of drug distribution as well as direct measurement within a granuloma[15, 16]. Rabbit models of TB show considerable variation in antibiotic concentrations between plasma, tissue and granulomas for four standard TB antibiotics[15]. For example, there is accumulation of moxifloxacin (a second-line anti-TB antibiotic) in the cellular cuff relative to the central caseum of necrotic granulomas[16]. Other antibiotics have been imaged in caseous lesions and exhibit heterogeneous patterns of intra-lesional distribution with either poor diffusion or accumulation into necrotic foci relative to the macrophage and lymphocyte cuff[17] (VC, unpublished data). A clinical trial is currently under way to evaluate permeability of several anti-TB antibiotics in resected lung tissue and granulomas of TB patients (ClinicialTrials.gov NCT00816426). Furthermore, work in non-human primates (NHPs) showed changes in granuloma pathology during treatment, suggesting changes in host-mediated mechanisms during treatment in response to changing bacterial populations[18]. Together, these results paint a picture of complex and variable antibiotic distribution concurrent with dynamic host immunity within granulomas. 
Standard therapy for active TB includes an initial combination of 3-4 first-line antibiotics for 2 months followed by another 4-7 months of 2 antibiotics. The firstline antibiotics for TB are isoniazid (INH), rifampin (RIF), pyrazinamide (PZA) and ethambutol (EMB), of which INH and RIF are the focus of this work. INH is a prodrug that, upon conversion to its active form, targets mycolic acid production (a component of bacterial cell wall) through inhibition of InhA (a 2-trans-enoyl-acyl carrier protein reductase). RIF targets bacterial RNA polymerase, inhibiting transcription. INH has been shown to have good early bactericidal activity but poor sterilizing activity, believed to be due to its high activity against replicating Mtb but low activity against non-replicating Mtb[19]. RIF has been shown to have good sterilizing activity[20]. RIF is effective against hypoxia- or acid-induced nonreplicating bacteria[21], but phenotypic tolerance develops in stress-induced nonreplicating bacteria[22] or stationary phase Mtb[23]. Overall, the complex dynamics of the bacteria, immune environment, and antibiotics, together with the expense of animal models and clinical trials, make evaluation of treatment protocols, regimens and drugs difficult. The technology required to follow antibiotic concentrations and bacterial numbers in a single granuloma over time does not exist.

In this work, we take a systems pharmacology approach to examine antibiotic therapy for TB. A number of plasma pharmacokinetic (PK) models for anti-TB antibiotics are available and range from one-compartment models to more complex physiology-based models[15, 24-26]. Combined PK-pharmacodynamics (PD) models for TB antibiotics have been built for RIF[27] and INH[28, 29] and non- 
specific antibiotics[30]. One previous model combining PK and PD of RIF with hostimmunity has been published but does not capture the added complexity of the granuloma in terms of structure, organization and antibiotic distribution[31].

Here we present the first computational platform for the study of antibiotic treatment of TB that integrates host immunity, PK (in plasma and lung tissue) and PD with spatial resolution. This platform provides a unique ability to probe mechanisms driving TB treatment outcomes. Identification of such mechanisms can drive the rational design of anti-TB antibiotics and regimens. We use this tool to address the following questions: What are antibiotic dynamics (distribution and activity) inside a lung granuloma? How does the spatial distribution of antibiotics within a granuloma influence treatment outcome? What are host mechanisms contributing to treatment outcome at a granuloma scale?

\section{Methods}

Our computational model includes (i) granuloma formation and function, (ii) antibiotic PK and (iii) antibiotic PD. We consider both plasma PK and lung tissue PK (i.e. antibiotic penetration into tissue). We outline each sub-model below and describe how we integrate them.

\section{Model of granuloma formation and function}

We use our established hybrid multi-scale agent-based model of Mtb infection and granuloma formation (GranSim). GranSim is based on extensive in vitro, mouse and non-human primate data as described previously [32-35]. Briefly, the model 
encapsulates molecular, cellular and tissue scale characteristics of a granuloma (Figure 1A). At the tissue scale, the model tracks chemokine-driven cellular movement on a 2D grid of micro-compartments. At the cellular scale, the model tracks individual macrophages and $\mathrm{T}$ cells, their states (resting, activated, infected or chronically infected for macrophages; and cytotoxic $\mathrm{T}$ cells, regulatory $\mathrm{T}$ cells or IFN- $\gamma$ producing T cells) and interactions. Host cell death contributes to caseation, and a grid micro-compartment is considered caseated when the cumulative number of host cell deaths in that compartment reaches a threshold. At the molecular level, the model tracks secretion, diffusion, binding and degradation of cytokines and chemokines. For example, we incorporate the pro-inflammatory cytokine tumor necrosis factor- $\alpha$ (TNF) and the anti-inflammatory cytokine interleukin-10 (IL-10), which drive immune cell communication and activation in tissues[32, 35-37]. To represent vasculature in lung tissue, a randomly-distributed number of microcompartments are designated vascular source micro-compartments (VSMs). Recruited host cells and antibiotics enter the grid exclusively through VSMs. The number of VSMs is calibrated to vasculature of NHP and human lung tissue. VSMs in areas of caseation and high cell density are deactivated in the simulation to account for lack of vascularization observed in vivo (Supplement, available online at http://malthus.micro.med.umich.edu/lab/movies/Abx/.).

Each macrophage and grid micro-compartment is assigned a continuous representation of the bacterial population in that location. Bacteria are in one of three sub-populations based on their location: intracellular $\left(B_{I}\right)$, replicating extracellular $\left(B_{E}\right)$ and non-replicating extracellular $\left(B_{N}\right)$ (Figure 1A). $B_{I}$ can grow, be 
killed within activated macrophages, or be killed when infected host cells they reside in undergo apoptosis or cytotoxic killing. When $B_{I}$ levels reach the carrying capacity of a macrophage, the macrophage bursts and distributes the bacteria to surrounding micro-compartments. $B_{E}$ can grow or be killed by macrophages in the same micro-compartment or by activated macrophages within their Moore neighborhood. Extracellular bacteria that reside in caseous micro-compartments are labeled 'non-replicating'. However, low levels of metabolic activity remain in these bacteria[40], and therefore we assign a slow growth rate to this subpopulation in the model (100-fold lower than $\left.B_{E}\right)$. The model can provide estimates of bacterial numbers, host dynamics, granuloma formation and caseation over time and is in agreement with granuloma data from TB-infected NHPs.

For the first time, in this work we use a 200x200 grid to better capture physiological granuloma sizes $(2 \pm 0.5 \mathrm{~mm}($ mean $\pm \mathrm{SD} ; \mathrm{N}=500))$ and vascular density $\left(185 \pm 13 \mathrm{~cm}^{2} / \mathrm{cm}^{3}\right.$ (mean $\left.\pm \mathrm{SD} ; \mathrm{N}=3\right)$ ) (see Supplement). We reduced the complexity in our description of TNF and IL-10 dynamics using our tunable resolution approach[41]. In addition, to reduce computational times $\sim 5$-fold, we implemented spectral methods for solving the partial differential equations describing diffusion $[42,43]$. The use of spectral methods in this model context, including comparison with other methods, is discussed in detail in [44]. This change made the hundreds of runs necessary for sensitivity analysis computationally feasible. These approaches, model calibration, and host parameter estimation are described in more detail in the Supplement. Baseline parameter values are given in Appendix A. 


\section{Plasma PK model structure}

We use a plasma PK model for INH and RIF that has been established in rabbits[15]. The model contains two distribution compartments, plasma and peripheral, and two transit compartments to capture oral absorption kinetics (Figure 1B, Appendix B). Antibiotic exposure is quantified using PK indices: AUC (area under the concentration curve), $C_{\max }$ (maximum concentration), $t_{\max }$ (time to $C_{\max }$ ) and $\mathrm{t}>\mathrm{MIC}$ (time above minimum inhibitory concentration).

\section{Tissue PK model structure}

Our model captures spatial distribution of antibiotics in lung tissue by accounting for diffusion and degradation within the tissue and penetration into and metabolism by host cells (Figure 1A). Degradation and metabolism in tissue does not contribute significantly to the overall elimination of the antibiotics, which is accomplished in the liver and accounted for in the plasma PK sub-model described above. We implement diffusion as we have done for other molecules[34, 45] (Cilfone et al., Submitted, Supplement). We assume that adjacent grids to the one under investigation would be similarly vascularized and therefore use insulating boundary conditions for antibiotic diffusion.

We assume cellular accumulation of antibiotics is at pseudo-steady state since previous estimated rates of antibiotic uptake are fast relative to diffusion[27]. Intracellular $\left(C_{i}\right)$ and extracellular concentrations $\left(C_{e}\right)$ are updated at each diffusion 
time step based on the total amount of antibiotic in the grid micro-compartment where each macrophage is located following diffusion. $C_{i}$ and $C_{e}$ are thus related by

$$
\begin{gathered}
C_{e}=\frac{A_{T}}{V_{\text {micro }}+a V_{\text {mac }}} \\
C_{i}=a C_{e}
\end{gathered}
$$

where $A_{T}$ is the total amount of antibiotic available (intracellular plus

extracellular), $V_{\text {micro }}$ is the volume of one micro-compartment, $V_{\text {mac }}$ is the volume of a macrophage and a is the cellular accumulation ratio (or intracellular partition coefficient). Antibiotics degrade in extracellular and are metabolized in intracellular environments with first order kinetics in (Appendix C).

\section{PD model structure}

PD parameters have been determined for several TB antibiotics in broth, in macrophage culture and in mice[38, 39, 46]. The concentration dependent antibacterial activity is quantified using an $E_{\max }$ model as in [Error! Hyperlink reference not valid.] (Figure 1C; Appendix D). Note that parameters are defined separately for intra- or extracellular populations since PD differ between these populations[38, 39].

\section{Combined model structure}

We link the four models described above (GranSim, plasma PK, tissue PK and PD) together to form our complete model of antibiotic treatment. Antibiotics are added to or subtracted from the VSMs on the GranSim grid depending on the 
concentration difference between the plasma concentration (Appendix B) and lung tissue (on the GranSim grid):

$$
C_{V S M}(t+\Delta t)=C_{V S M}(t)+p A_{V S M}\left(P C \times C_{P}(t)-C_{V S M}(t)\right) \Delta t
$$

where $C_{V S M}$ is antibiotic concentration on the grid at the given VSM (mg/L), $p$ is permeability $(\mathrm{cm} / \mathrm{s}), A_{V S M}$ is outside area of the grid micro-compartment $\left(\mathrm{cm}^{2}\right), P C$ is permeability coefficient (measure of antibiotic sequestration in the tissue) and $\Delta t$ is time step (s). Note: $C_{e}=C_{V S M}$ at VSMs. We do not update the plasma concentrations in the plasma PK ODEs based on these calculations because the size of the simulation grid $(4 \mathrm{~mm} \times 4 \mathrm{~mm})$ is negligible relative to the volume of plasma compartment. The influence of bulk lung tissue on plasma concentrations is captured by the peripheral distribution (at rate constant $Q$ ) in the plasma PK model (Figure 1B).

PD is linked to PK via the local antibiotic concentrations as determined by the combined plasma and tissue PK models. PD is linked to GranSim by subtracting the killing rate from the growth rate for each Mtb subpopulation per agent time-step. Changes in the Mtb subpopulation $\left(B_{x}\right)$ due to growth and killing are expressed as in[48]:

$$
\frac{d B_{x}}{d t}=\left(g_{x}-k_{\text {kill }, x}\right) B_{x}
$$

where $g_{x}$ is the growth rate constant for bacterial subpopulation $x$.

\section{Simulating antibiotic treatment regimens}

We simulate a 6-month daily regimen of INH or RIF as recommended by the Centers for Disease Control and Prevention[49]. Granulomas are allowed to form 
and grow for 100 days post infection (d.p.i). Treatment is initiated at 100 d.p.i. by adding a daily dose of INH or RIF to the first transit compartment of the plasma PK model (Figure 1B). Granulomas are classified as 'cleared' when there are no bacteria remaining in the granuloma after 180 days of treatment; otherwise they are considered 'not cleared'.

\section{Model implementation}

The model was constructed using the $\mathrm{C}++$ programming language with Boost (distributed under the Boost Software License - available at www.boost.org) and FFTw libraries (distributed under GPL - available at www.fftw.org). The graphical user interface (GUI), which allows us to visualize, track, and plot different facets of our simulated granulomas in real-time was built using the Qt framework (opensource, distributed under GPL - available at qt.digia.com). Post-processing for visualization was carried out on multi-core desktops and laptops.

\section{Sensitivity analysis}

We implement uncertainty and sensitivity analysis methods as described in[50]. Our uncertainty analysis identifies the breadth of outcomes produced by the model using Latin hypercube parameter sampling (LHS). We apply two sensitivity analysis approaches, partial rank correlation coefficients (PRCC) and eFAST (see Supplement and [50]). PRCC and eFAST measure sensitivity in different ways: PRCC identifies significance and directions (positive or negative) of correlations between parameters and outputs and eFAST identifies sources of variation in model outputs. 
For host-specific PRCC analysis (to identify the most influential host parameters during treatment), we vary 58 host parameters simultaneously and parameters are sampled 500 times (Appendix A). For antibiotic-specific PRCC analysis (to identify the most influential antibiotic parameters), we vary 20 parameters, sampled 300 times (Appendix E) with three replications. The average output values are used in the PRCC analysis. We compare strengths of correlations by applying a z-test to pairs of correlation coefficients. A p-value $<0.01$ is considered significant for PRCC and z-tests.

For eFast analysis, we vary 20 antibiotic-specific parameters in the same ranges as used for PRCC with 3 re-samplings, 65 sample curves and 3 replications. We perform analysis as in [50] using scripts provided at http://malthus.micro.med.umich.edu/lab/usadata/.

\section{Naïve Bayes classification.}

We also wish to perform classification, i.e. be able to predict model outputs based on a defined set of known, measurable features. Specifically for our model, it is useful to be able to predict treatment outcomes based on early time point outputs. Bayes classification is a probabilistic classification method that constructs probability distributions for a predetermined list of features (inputs) for each class (output) of interest based on a training data set. These distributions are used to calculate the probability of observations in a test data set being in each class, conditional on their sets of features. Observations are assigned the class with the highest probability. Naïve Bayes Classification was selected instead of non- 
probabilistic clustering methods (SVM, k-means clustering), which did not perform well on our data (not shown). This is often the case for complex systems[51, 52]. We use Bayes classification to predict treatment outcome (cleared vs not cleared) based on pre-treatment characteristics of granulomas as features. We include an initial list of 63 pre-treatment granuloma characteristics as features. The features are ranked based on their individual predictive accuracy, and filtered using sequential feature selection to identify the key features (Table S4). The accuracy of the resulting model is estimated using a 10-fold cross validation[53]. Our Bayes model is evaluated based on its minimum accuracy in predicting cleared and not cleared granulomas (see Supplement).

\section{Results}

We constructed a model of INH and RIF distribution and action in granulomas (Figure 1). To our knowledge this is the first PK-PD model of antibiotic penetration into granulomas with temporal-spatial resolution. We first calibrate the model to experimental data from well-studied animal models of TB.

\section{Model calibration to animal models of TB}

We calibrate each component of the combined model individually to animal model data available on a granuloma level[$[4,15,18]$. Note that the sub-model GranSim describing granuloma formation and function in the absence of antibiotics has been previously calibrated to NHP granuloma data (Cilfone et al. Submitted and Supplement). First, we calibrate plasma PK parameters by comparing three indices 
(AUC, Cmax and tmax; Figure 1B) derived from simulations to those measured for INH and RIF in NHPs[18]. NHP most accurately reproduce human disease and pathology $[54,55]$, and we use data from NHPs for calibration whenever available. We sample the relevant parameter space (see Supplement), simulate 4 daily doses of INH (15 mg/kg) or RIF (20 mg/kg), and measure PK indices for the fourth dose as in [18]. These doses for NHPs emulate human plasma exposure levels. Out of 700 parameter combinations created using LHS, we identified 14 combinations that give AUC, $C_{\max }$ and $t_{\max }$ within one standard deviation of the experimental mean. We then set ranges for each parameter to encompass all values from the set of 14 (Appendix E). Experimental and model outcomes for PK indices are shown in Figure 2A. We use ranges for each parameter instead of single values to capture the experimentally observed variation in plasma PK[18]. Our parameter ranges agree with known PK differences between INH and RIF. A combination of higher clearance rates, higher peripheral volumes of distribution and higher absorption rates for INH lead to INH concentrations that peak earlier than RIF and that do not accumulate significantly with repeated dosing, unlike RIF[15, 18, 56-58].

Second, we estimate lung tissue PK parameters. Intra-granuloma antibiotic concentrations are so far only available for rabbit granulomas[15], so we use rabbit data for tissue PK calibration only. We minimize any risk of errors from mixing animal models by using rabbit plasma PK parameters and doses $(30 \mathrm{mg} / \mathrm{kg}$ for INH and $24 \mathrm{mg} / \mathrm{kg}$ for RIF) when estimating tissue PK parameters. Thus we assume that antibiotics move similarly within in lung tissue in rabbits and NHPs. We calibrate the model using normal lung tissue and granuloma AUC by sampling parameter 
space for tissue PK parameters (Appendix E). PK indices were measured after 12 days of treatment (as in [15]). Out of 1000 parameter combinations, parameter values were selected that minimized differences between experimental measurements and model predictions of AUC ratios relative to plasma (Figure 2B; Appendix E; Supplement). Limited data on INH and RIF distribution in the caseum or cavity wall of rabbit granulomas indicate that INH accumulates in caseum while RIF has higher concentration in the cavity wall (V. Dartois, unpublished observations). It is difficult to delineate the outline of 'caseum' or 'cavity wall' areas in simulated granulomas. Nonetheless, parameter values from the model calibration are in line with these observations, i.e. low cellular accumulation ratio for INH and high cellular accumulation ratio for RIF, meaning RIF is more likely to accumulate in cellular areas of the granuloma.

Third, we calibrate the PD sub-model by comparing simulated outcomes after 60 days of treatment with INH or RIF to data from NHPs[4]. Five hundred simulated granulomas are obtained by varying host parameters to give a distribution of total Mtb per granuloma similar to that observed in NHP granulomas at a median of 160 days post infection (d.p.i.) (Figure 2C; Appendix E; Supplement)[4]. Treatment is initiated in the simulated granulomas at 100 d.p.i.. In the absence of in vivo dose response curves, $C_{50}$ and $H$ are estimated from in vitro dose response curves for INH and $\operatorname{RIF}[23,38,39,59]$ with the caveat that these parameters may not extrapolate to in vivo conditions, and that they can vary between strains. $E_{\max }$ values are selected that reproduce INH and RIF efficacy in NHPs after 2 months of daily dosing in terms of mean CFU and percentage of granulomas cleared[4]. As with the calibration to 
determine plasma PK parameters, we use doses that emulate human plasma PK in NHPs.

This calibrated combined model finalizes our computational tool that can now be used to simulate a daily dosing regimen and make predictions about treatment progression and outcomes.

Mean INH concentrations in granulomas only exceed $C_{50}$ for short periods and mean RIF concentrations do not exceed $C_{50, B I}$ or $C_{50, B N}$

We use our model to simulate a daily dosing regimen similar to that recommended by the $\mathrm{CDC}$ for treatment of active $\mathrm{TB}$ [49] to determine granuloma scale dynamics of all cells and antibiotics. Of particular interest is how antibiotic concentrations vary over time, as measured against $C_{50}$ (an indication of the 'effective' concentrations of each antibiotic for each bacterial subpopulation). Average antibiotic concentrations per granuloma over seven days of treatment are shown in Figure 3. The short half-life of INH in granulomas, due primarily to the high plasma clearance rate constant $C L$ (giving a half-life of $\sim 1$ hour), leads to average concentrations below $C_{50, B I}$ and $C_{50, B E}$ for $>80 \%$ of the dosing period. Peak INH concentrations barely reach $C_{50, B N}$. The longer half-life of RIF in granulomas, due primarily to a lower plasma clearance rate constant $C L$, and high permeability coefficient $P C$, lead to concentrations below $C_{50, B E}$ for only $37 \%$ of the dosing period. However, RIF concentrations never exceed $C_{50, B N}$ or $C_{50, B I}$ inside the granuloma. These suboptimal antibiotic exposures could contribute to treatment failure. 


\section{Bacterial regrowth occurs between doses and is greater for INH than RIF}

We are able to track bacterial dynamics inside simulated granulomas; this is not possible to do experimentally. INH treatment leads to a sharp decrease in CFU immediately after dosing (Figure 3A), followed by bacterial regrowth once antibiotic concentrations drop below $C_{50, B E}$ and $C_{50, B I}$. RIF treatment leads to a more consistent decrease in total CFU (Figure 3B) than INH treatment due to the slower plasma clearance rate constant for RIF as well as the larger Hill constant for INH (Appendix E). If we continue the simulation to 280 d.p.i. (180 days of treatment) we can make two predictions. First, RIF treatment sterilizes more granulomas (93\%) than INH treatment (86\%) after 180 days of treatment. And second, there appears to already be a separation between the granulomas that will/will not sterilize during treatment prior to treatment start (Figures 4A and 4B), suggesting that pretreatment bacterial load may play a role in treatment outcome.

We also predict dynamics of individual bacterial sub-populations within granulomas during treatment. During the first 7 days of RIF and INH treatment, the proportion of bacteria that are intracellular increases (Figure 3). This is due to low INH and RIF concentrations inside cells relative to $C_{50, B I}$ as discussed above. Furthermore, continued phagocytosis of extracellular bacteria during treatment adds to the protected intracellular population. Over 280 days, the dominant subpopulation starts to change after $\sim 10$ days (Figure 4C and 4D). The trend is slow, and after 30 days of daily INH or RIF treatment the majority of bacteria are nonreplicating extracellular bacteria, i.e. bacteria trapped in hypoxic caseum. Results are similar for INH and RIF. These changes in relative bacterial sub-populations over 
time present a moving target for drug regimens and could lead to changes in treatment efficacy.

\section{Antibiotic concentration gradients form inside granulomas}

Current technology is just now beginning to allow observation of the spatial distribution of antibiotics in granulomas[17]. With our computational model, we can visualize and track details of the spatial distribution of antibiotics in simulated granulomas and also do this over time, giving the ability to calculate cumulative antibiotic exposure (here calculated as AUC - see Methods) for all parts of a granuloma. Two sample granulomas treated with daily INH or RIF are shown in Figure 5. Time-lapse movies of drug distributions and treatment progression within these granulomas, as well as high-resolution images that better show cellular level details (such as T-cells and caseation) are available at http://malthus.micro.med.umich.edu/lab/movies/Abx/. Figure 5A shows a sample solid cellular granuloma of diameter $1.7 \mathrm{~mm}$ at day 100 , when simulated treatment with antibiotics is initiated. INH and RIF exposures during the first week of treatment are significantly lower inside the granuloma than in the surrounding tissue, are well below the $24 \mathrm{hr}$ AUC $E C_{80}$ (AUC that achieves $80 \%$ of maximum killing, maximum on color scales in Figure 5). Noticeable antibiotic concentration gradients form inside the granuloma. Despite low exposure to both INH and RIF inside the granuloma, $\mathrm{CFU}$ is reduced and the granuloma shrinks from $1.7 \mathrm{~mm}$ to 1.4 mm diameter by day 160 for both antibiotics. For all simulated granulomas, predicted changes in granuloma size during treatment match NHP data[4] (data not 
shown). For this granuloma, RIF treatment clears bacteria by day 280 while INH treatment does not. Snapshots of 260 d.p.i as well as spatial antibiotic distributions at 160 and 260 d.p.i are available in the Supplement. As the granuloma shrinks, the area of suboptimal exposure decreases.

Figure 5B shows a sample caseous granuloma of diameter $2 \mathrm{~mm}$. INH and RIF exposure look qualitatively similar to Figure $5 \mathrm{~A}$; however, the area of suboptimal INH exposure is larger in the granuloma in Figure 5B. This is a result of the combined effects of larger granuloma size, lower absorption rate constant and higher inter-compartmental and plasma clearance rate constants than the granuloma shown in Figure 5A (see Table S7). In this case, INH and RIF are less efficient at reducing CFU after 60 days of treatment, and both antibiotics fail to clear bacterial load by day 280. During INH treatment the granuloma size remains at $2 \mathrm{~mm}$ until the end of treatment, and during RIF treatment the granuloma shrinks to $1.7 \mathrm{~mm}$ by day 160 but no further. Because INH fails to shrink the granuloma, exposure remains nearly constant over the treatment period while there is a slight improvement in antibiotic exposure for RIF treatment over time.

Average antibiotic exposure in all simulated granulomas is shown in Figure 6. We predict a wide range of exposure to both INH and RIF, with $91 \%$ and $100 \%$ of granulomas, treated with INH and RIF respectively, predicted to fall below the $24 \mathrm{hr}$ AUC $E C_{80}$.

Taken together, our predictions show that suboptimal INH and RIF exposure exists inside granulomas, especially in areas where bacteria reside, and this contributes to a slow rate of bacterial clearance. If early treatment can succeed in 
shrinking granuloma size, antibiotic exposure improves over time and helps clear the bacterial load.

\section{Factors predictive of treatment outcomes}

One benefit of using a systems pharmacology approach is being able to perform analyses on our model to identify factors that drive different outcomes. We use three such approaches (PRCC, eFAST and Bayes classification) to identify both pre-treatment and during-treatment factors in three areas: host, bacterial or antibiotic. We summarize our results in Table 1. Parameters are grouped for clarity and groups are defined in Table S2.

Pre-treatment host factors that are predictive of treatment outcomes are related to severity of infection (host cell recruitment, granuloma size and caseation) and host ability to control bacterial load (TNF-induced apoptosis, T cell-mediated killing, macrophage and T cell activation) (see Table S2). Many of these host factors continue to play a role once treatment is initiated. The probability of resting macrophages phagocytosing and killing extracellular bacteria is significantly negatively correlated with bacterial load in treated granulomas. This suggests that as treatment reduces bacterial load, macrophage activation decreases and the relative role of resting macrophage uptake and processing of bacteria increases. Indeed, looking at non antibiotic-mediated killing mechanisms, the proportion of bacteria that are killed by activated macrophages is significantly lower in treated granulomas, and the proportion killed by resting macrophages is higher in treated granulomas (Figure S6). 
Two pre-treatment bacterial factors that predict treatment outcome, the numbers of intracellular bacteria and non-replicating extracellular bacteria, are both related to severity of infection within a granuloma. The average time bacteria spend inside macrophages before they are killed or released is positively correlated with cumulative bacterial burden before and during treatment.

Finally, antibiotic exposure is identified as a driving feature during treatment. The key mechanisms behind antibiotic exposure and activity include plasma PK, tissue PK and PD parameters (Table 1, see Table S3). Taken together, these results indicate that both host and bacterial attributes continue to play important roles during antibiotic treatment.

\section{Discussion}

We present the first systems pharmacology approach to modeling antibiotic treatment of TB that integrates a spatio-temporal model of granuloma formation and function with models of antibiotic plasma PK, lung tissue PK, and PD. Granulomas, the central feature of Mtb infection, are now known to present heterogeneous and dynamic microenvironments that may influence treatment outcome $[17,60]$. Our approach allows us to probe the distribution, dynamics, and effects of antibiotics within these pathological structures. Our integrated model is made possible by the development of our spatial model of TB granulomas[32-35], novel measurements of anti-TB antibiotics in granulomas[15, 16], and pergranuloma bacterial numbers from Mtb-infected and treated NHPs[3, 4]. 
Computational methods are a necessary complement to experimental efforts moving forward in the fight against TB. The combined complexities of the pathogen, disease pathology, immune system, antibiotic dynamics and host variation make it virtually impossible to disentangle the numerous driving forces behind infection outcomes using only animal and human data. Our modular model captures and integrates these dynamics to help translate biomedical mechanisms to clinical relevance. Furthermore, experimental data are often sparse, and computational models can be used to expand the explanatory power of limited experimental data.

We characterize both the spatial and temporal activity of two first-line antibiotics, INH and RIF at doses that emulate human dynamics. Our predicted spatial distributions for INH and RIF are in agreement with observed concentration gradients of another antibiotic, moxifloxacin, in rabbit granulomas[16], and such heterogeneous distributions are likely to be factor for many anti-TB antibiotics. We show that suboptimal exposure inside simulated granulomas leads to bacterial regrowth between doses and may contribute to long-term treatment requirements for TB. There have been other proposed reasons for the required long-term antibiotic usage in $\mathrm{TB}$, such as protected bacterial subpopulations that are in a nonreplicating state[61] and/or are intracellular[31]. These bacterial subpopulations are believed to be relatively protected from INH and RIF activity, respectively, compared to replicating extracellular bacteria. However, our analysis shows that numbers and location of protected subpopulations change over time and that similar subpopulations are protected in both INH- and RIF-treated granulomas. Target bacterial populations change significantly (albeit slowly) during treatment, 
suggesting that a switch in treatment strategies, to match the change in target population, after several weeks of treatment could be beneficial.

Identification of key mechanisms behind treatment outcomes indicates that pretreatment bacterial load is an important correlate of treatment outcome. There is clinical evidence to support the importance of pre-treatment bacterial load in humans [62]. More complex pathologies, such as TB pneumonia, consolidations, and cavities, which also significantly contribute to overall host bacterial burden[54,55] and are related to disease severity, are currently outside the scope of this model but could strengthen this correlation. This threshold in bacterial burden is analogous to the thresholds or infectious doses reported for e.g. anthrax spores or pseudomonads. The thresholds represent a limit of how many pathogens can be cleared by the immune system (or in our case antibiotics together with the immune system). Many dosing regimes are currently in use, and the decision regarding which to prescribe is currently made based on the following considerations: social, logistical, host disease status such as cavitation before treatment, microbiological findings after 2 months of treatment[49, 63]. Sputum smear rating (based on the number of microscopically visible bacteria in a sputum sample) at diagnosis could be included in the regimen decision-making process, although the relationship between sputum and granuloma bacterial burden is not known.

During treatment, as expected, the model predicts that antibiotic exposure is a key determinant of treatment outcome, implying that increased dose size would improve treatment outcome. Toxicity is a concern at high doses, limiting the dose that can safely be given orally. Drug delivery via nanoparticles has the potential to 
improve antibiotic exposure while limiting systemic toxicity [64]. We also predict the continued significance of host mechanisms during treatment. Identification and ranking of these host mechanisms identifies potential targets for immunotherapy. Potential strategies include recombinant cytokines or bacterial components to boost host immunity[65]. Specifically, immunotherapy could aim to boost macrophage activation during treatment, when decreasing bacterial load leads to lower levels of activation; or to release bacteria from protected niches. Bacterial load and drug penetration into the site of infection are also key indicators of reactivation during anti-TNF treatment[45, 66]. Therefore, host mechanisms, bacterial load and drug permeability need to be considered as part of the design space combining immunemodulation together with antibiotic treatment of TB[67-69].

Although emergence of antibiotic resistance is outside the scope of this work, both theoretical[70] and experimental[71] work has shown that existence of antibiotic concentration gradients accelerates resistance development in bacterial populations. The predicted antibiotic concentration gradients within granulomas, as well as extended exposure of bacteria to suboptimal antibiotic concentrations and periods of unintentional monotherapy could therefore contribute to development of drug-resistance. As part of a more detailed model of bacterial phenotypes, we are exploring drug-resistance development in granulomas, and the predicted effects of non-compliance on drug-resistance[72].

Fidelity of the model for application to human disease can be improved as more data become available. Whenever possible, we calibrate the model to data in NHPs. Although NHPs are the animal that most closely resembles human disease in 
pathology and progression[54], this correlation may be imperfect. Tissue PK measurements are currently only available for rabbits[15], so we assume that antibiotic penetration into lung tissue in rabbit and NHP lungs are similar. RIF is known to induce its own metabolism with continuous administration[73], but this mechanism is not included in the current model for the sake of simplicity. This implies that our conclusions about the efficacy of RIF in this model are conservative estimates as increases in metabolism would decrease RIF availability to a greater extent. PD parameters were estimated from in vitro data because in vivo parameters are not available, and these parameters may not extrapolate well to in vivo conditions.

The model components included in this integrated computational tool make it ideal to examine TB treatment from three angles. First, the model can be used predict intra-granuloma activity for new antibiotics and suggest possible improvements to current antibiotics to improve their efficacy. This advantage can help identify drug candidates that look promising in vitro but will have poor in vivo activity. Second, since multi-drug treatment is a cornerstone of TB therapy, the model can easily test a large number of antibiotics and antibiotic combinations and dosing regimens, which can guide the choices of new combinations and regimens to be tested in costly animal and human trials. Finally, the inclusion of host immunity enables the exploration of immunotherapeutic strategies (the targeted manipulation of the host immune response to reduce bacterial load)[65], alone or in combination with antibiotics. 
Clinical trials of antibiotics for TB remain fraught with limitations, including the inability to test drugs singly or in combinations, cost, and the length of clinical trials. Animal models play an important role in the identification of new and effective regimens, but these studies are also time-consuming and costly, and they require models with human-like pathology, primarily NHPs. Here we provide a complementary systems pharmacology tool for predicting the efficacy of new drugs and regimens, allowing a rapid assessment of drug efficacy at the site of bacterial growth and persistence, the granuloma.

\section{Acknowledgments}

This research used the following resources: National Energy Research Scientific Computing Center, which is supported by the Office of Science of the U.S. Department of Energy under Contract No. DE-AC02-05CH11231; Open Science Grid, which is supported by the National Science Foundation and the U.S. Department of Energy's Office of Science; and Nyx/Flux computing cluster available at the Center for Advanced Computing at the University of Michigan. This research was supported by: NIH R01 HL106804 (awarded to DEK and JLF), R01 EB012579 (awarded to DEK, JLF and JJL), and R01 HL 110811 (awarded to DEK, JLF and JJL), and the Bill and Melinda Gates Foundation TB Drug Accelerator program (JLF and VD), and TB Drug Accelerator OPP066499 (VD). 


\section{References}

1. McFee, R.B., Update - pathogens of concern. Dis Mon, 2013. 59(12): p. 437-8.

2. WHO, Global tuberculosis report, 2013.

3. Lin, P.L., et al., Sterilization of granulomas is common in active and latent tuberculosis despite within-host variability in bacterial killing. Nat Med, 2014. 20(1): p. 75-9.

4. Lin, P.L., et al., Radiologic responses in cynomolgous macaques for assessing tuberculosis chemotherapy regimens. Antimicrob Agents Chemother, 2013.

5. Emile, J.F., et al., Correlation of granuloma structure with clinical outcome defines two types of idiopathic disseminated BCG infection. J Pathol, 1997. 181(1): p. 25-30.

6. Ridley, M.J., et al., Experimental epithelioid cell granulomas, tubercle formation and immunological competence: an ultrastructural analysis. J Pathol, 1983. 141(2): p. 97-112.

7. Lin, P.L., et al., Early events in Mycobacterium tuberculosis infection in cynomolgus macaques. Infect Immun, 2006. 74(7): p. 3790-803.

8. Barry, C.E., 3rd, et al., The spectrum of latent tuberculosis: rethinking the biology and intervention strategies. Nat Rev Microbiol, 2009. 7(12): p. 845-55.

9. Via, L.E., et al., Tuberculous granulomas are hypoxic in guinea pigs, rabbits, and nonhuman primates. Infect Immun, 2008. 76(6): p. 2333-40.

10. Garton, N.J., et al., Cytological and transcript analyses reveal fat and lazy persister-like bacilli in tuberculous sputum. PLoS Med, 2008. 5(4): p. e75.

11. Dartois, V., Drug forgiveness and interpatient pharmacokinetic variability in tuberculosis. J Infect Dis, 2011. 204(12): p. 1827-9.

12. Kislitsyna, N.A., [Comparative evaluation of rifampicin and isoniazid penetration into the pathological foci of the lungs in tuberculosis patients]. Probl Tuberk, 1985(4): p. 55-7.

13. Kislitsyna, N.A. and N.I. Kotova, [Rifampicin and isoniazid concentration in the blood and resected lungs in tuberculosis with combined use of the preparations]. Probl Tuberk, 1980(8): p. 63-5.

14. Barclay, W.R., et al., Distribution and excretion of radioactive isoniazid in tuberculous patients. J Am Med Assoc, 1953. 151(16): p. 1384-8.

15. Kjellsson, M.C., et al., Pharmacokinetic evaluation of the penetration of antituberculosis agents in rabbit pulmonary lesions. Antimicrob Agents Chemother, 2012. 56(1): p. 446-57.

16. Prideaux, B., et al., High-sensitivity MALDI-MRM-MS imaging of moxifloxacin distribution in tuberculosis-infected rabbit lungs and granulomatous lesions. Anal Chem, 2011. 83(6): p. 2112-8.

17. Dartois, V., The path of anti-tuberculosis drugs: from blood to lesions to mycobacterial cells. Nat Rev Microbiol, 2014. 12(3): p. 159-67. 
18. Lin, P.L., et al., Metronidazole prevents reactivation of latent Mycobacterium tuberculosis infection in macaques. Proc Natl Acad Sci U S A, 2012. 109(35): p. 14188-93.

19. Zumla, A., P. Nahid, and S.T. Cole, Advances in the development of new tuberculosis drugs and treatment regimens. Nat Rev Drug Discov, 2013. 12(5): p. 388-404.

20. Jindani, A., C.J. Dore, and D.A. Mitchison, Bactericidal and sterilizing activities of antituberculosis drugs during the first 14 days. Am J Respir Crit Care Med, 2003. 167(10): p. 1348-54.

21. Piccaro, G., et al., Activities of drug combinations against Mycobacterium tuberculosis grown in aerobic and hypoxic acidic conditions. Antimicrob Agents Chemother, 2013. 57(3): p. 1428-33.

22. Deb, C., et al., A novel in vitro multiple-stress dormancy model for Mycobacterium tuberculosis generates a lipid-loaded, drug-tolerant, dormant pathogen. PLoS One, 2009. 4(6): p. e6077.

23. de Steenwinkel, J.E., et al., Time-kill kinetics of anti-tuberculosis drugs, and emergence of resistance, in relation to metabolic activity of Mycobacterium tuberculosis. J Antimicrob Chemother, 2010. 65(12): p. 2582-9.

24. Egelund, E.F., A.B. Barth, and C.A. Peloquin, Population pharmacokinetics and its role in anti-tuberculosis drug development and optimization of treatment. Curr Pharm Des, 2011. 17(27): p. 2889-99.

25. Lyons, M.A., et al., A physiologically based pharmacokinetic model of rifampin in mice. Antimicrob Agents Chemother, 2013. 57(4): p. 1763-71.

26. Reisfeld, B., et al., A physiologically based pharmacokinetic model for capreomycin. Antimicrob Agents Chemother, 2012. 56(2): p. 926-34.

27. Goutelle, S., et al., Population modeling and Monte Carlo simulation study of the pharmacokinetics and antituberculosis pharmacodynamics of rifampin in lungs. Antimicrob Agents Chemother, 2009. 53(7): p. 2974-81.

28. Budha, N.R., et al., A simple in vitro PK/PD model system to determine time-kill curves of drugs against Mycobacteria. Tuberculosis (Edinb), 2009. 89(5): p. 378-85.

29. Lemmer, Y., et al., A Model of Isoniazid Treatment of Tuberculosis. Journal of Theoretical Biology, 2014. In press.

30. Lipsitch, M. and B.R. Levin, The population dynamics of antimicrobial chemotherapy. Antimicrob Agents Chemother, 1997. 41(2): p. 363-73.

31. Goutelle, S., et al., Mathematical modeling of pulmonary tuberculosis therapy: Insights from a prototype model with rifampin. J Theor Biol, 2011. 282(1): p. 80-92.

32. Ray, J.C., J.L. Flynn, and D.E. Kirschner, Synergy between individual TNFdependent functions determines granuloma performance for controlling Mycobacterium tuberculosis infection. J Immunol, 2009. 182(6): p. 3706-17.

33. Segovia-Juarez, J.L., S. Ganguli, and D. Kirschner, Identifying control mechanisms of granuloma formation during M. tuberculosis infection using an agent-based model. J Theor Biol, 2004. 231(3): p. 357-76. 
34. Cilfone, N.A., et al., Multi-scale modeling predicts a balance of tumor necrosis factor-alpha and interleukin-10 controls the granuloma environment during Mycobacterium tuberculosis infection. PloS one, 2013. 8(7): p. e68680.

35. Fallahi-Sichani, M., et al., Multiscale computational modeling reveals a critical role for TNF-alpha receptor 1 dynamics in tuberculosis granuloma formation. J Immunol, 2011. 186(6): p. 3472-83.

36. Flynn, J.L., et al., Tumor necrosis factor-alpha is required in the protective immune response against Mycobacterium tuberculosis in mice. Immunity, 1995. 2(6): p. 561-72.

37. Kaneko, H., et al., Role of tumor necrosis factor-alpha in Mycobacteriuminduced granuloma formation in tumor necrosis factor-alpha-deficient mice. Lab Invest, 1999. 79(4): p. 379-86.

38. Jayaram, R., et al., Pharmacokinetics-pharmacodynamics of rifampin in an aerosol infection model of tuberculosis. Antimicrob Agents Chemother, 2003. 47(7): p. 2118-24.

39. Jayaram, R., et al., Isoniazid pharmacokinetics-pharmacodynamics in an aerosol infection model of tuberculosis. Antimicrob Agents Chemother, 2004. 48(8): p. 2951-7.

40. Boshoff, H.I. and C.E. Barry, 3rd, Tuberculosis - metabolism and respiration in the absence of growth. Nat Rev Microbiol, 2005. 3(1): p. 70-80.

41. Kirschner, D.E., et al., Tuneable resolution as a systems biology approach for multi-scale, multi-compartment computational models. Wiley Interdiscip Rev Syst Biol Med, 2014. 6(4): p. 289-309.

42. Mugler, D.H. and R.A. Scott, Fast fourier transform method for partial differential equations, case study: The 2-D diffusion equation. Computers \& Mathematics with Applications, 1988. 16(3): p. 221-228.

43. Costa, B., Spectral methods for partial differential equations. CUBO, 2004. 6(4): p. 1-32.

44. Cilfone, N.A., D.E. Kirschner, and J.J. Linderman, Strategies for efficient numerical implementation of hybrid multi-scale agent-based models to describe biological systems (Accepted pending minor revisions). Cellular and Molecular Bioengineering, 2014.

45. Fallahi-Sichani, M., et al., Differential risk of tuberculosis reactivation among anti-TNF therapies is due to drug binding kinetics and permeability. J Immunol, 2012. 188(7): p. 3169-78.

46. Shandil, R.K., et al., Moxifloxacin, ofloxacin, sparfloxacin, and ciprofloxacin against Mycobacterium tuberculosis: evaluation of in vitro and pharmacodynamic indices that best predict in vivo efficacy. Antimicrob Agents Chemother, 2007. 51(2): p. 576-82.

47. Bouvier d'Yvoire, M.Y. and P. Maire, Dosage Regimens of Antibacterials. Clinical Drug Investigation, 1996. 11(4): p. 229-239.

48. Regoes, R.R., et al., Pharmacodynamic functions: a multiparameter approach to the design of antibiotic treatment regimens. Antimicrob Agents Chemother, 2004. 48(10): p. 3670-6. 
49. Blumberg, H.M., et al., American Thoracic Society/Centers for Disease Control and Prevention/Infectious Diseases Society of America: treatment of tuberculosis. Am J Respir Crit Care Med, 2003. 167(4): p. 603-62.

50. Marino, S., et al., A methodology for performing global uncertainty and sensitivity analysis in systems biology. J Theor Biol, 2008. 254(1): p. 178-96.

51. Rish, I., An empirical study of the naive Bayes classifier, 2001.

52. Domingos, P. and M. Pazzani, On the Optimality of the Simple Bayesian Classifier under Zero-One Loss. Machine Learning, 1997. 29(2-3): p. 103-130.

53. Kohavi, R., A study of cross-validation and bootstrap for accuracy estimation and model selection. Proceedings of the 14th international joint conference on Artificial intelligence - Volume 2.1995, Montreal, Quebec, Canada: Morgan Kaufmann Publishers Inc. 1137-1143.

54. Capuano, S.V., 3rd, et al., Experimental Mycobacterium tuberculosis infection of cynomolgus macaques closely resembles the various manifestations of human M. tuberculosis infection. Infect Immun, 2003. 71(10): p. 5831-44.

55. Lin, P.L., et al., Quantitative comparison of active and latent tuberculosis in the cynomolgus macaque model. Infect Immun, 2009. 77(10): p. 4631-42.

56. Peloquin, C.A., et al., Population pharmacokinetic modeling of isoniazid, rifampin, and pyrazinamide. Antimicrob Agents Chemother, 1997. 41(12): $\mathrm{p}$. 2670-9.

57. Wilkins, J.J., et al., Population pharmacokinetics of rifampin in pulmonary tuberculosis patients, including a semimechanistic model to describe variable absorption. Antimicrob Agents Chemother, 2008. 52(6): p. 2138-48.

58. Wilkins, J.J., et al., Variability in the population pharmacokinetics of isoniazid in South African tuberculosis patients. Br J Clin Pharmacol, 2011. 72(1): p. 5162.

59. Gumbo, T., et al., Isoniazid bactericidal activity and resistance emergence: integrating pharmacodynamics and pharmacogenomics to predict efficacy in different ethnic populations. Antimicrob Agents Chemother, 2007. 51(7): p. 2329-36.

60. Peloquin, C., What is the 'right' dose of rifampin? Int J Tuberc Lung Dis, 2003. 7(1): p. 3-5.

61. Connolly, L.E., P.H. Edelstein, and L. Ramakrishnan, Why is long-term therapy required to cure tuberculosis? PLoS Med, 2007. 4(3): p. e120.

62. Lienhardt, C., et al., Factors determining the outcome of treatment of adult smear-positive tuberculosis cases in The Gambia. Int J Tuberc Lung Dis, 1998. 2(9): p. 712-8.

63. Wallis, R.S., et al., Month 2 culture status and treatment duration as predictors of tuberculosis relapse risk in a meta-regression model. PLoS One, 2013. 8(8): p. e71116.

64. Griffiths, G., et al., Nanobead-based interventions for the treatment and prevention of tuberculosis. Nat Rev Microbiol, 2010. 8(11): p. 827-34.

65. Uhlin, M., et al., Adjunct immunotherapies for tuberculosis. J Infect Dis, 2012. 205 Suppl 2: p. S325-34. 
66. Marino, S., et al., Differences in reactivation of tuberculosis induced from antiTNF treatments are based on bioavailability in granulomatous tissue. PLoS Comput Biol, 2007. 3(10): p. 1909-24.

67. Iseman, M.D., Tuberculosis therapy: past, present and future. Eur Respir J Suppl, 2002. 36: p. 87s-94s.

68. Rivero-Lezcano, O.M., Cytokines as immunomodulators in tuberculosis therapy. Recent Pat Antiinfect Drug Discov, 2008. 3(3): p. 168-76.

69. Linderman, J.J. and D.E. Kirschner, In silico models of M. tuberculosis infection provide a route to new therapies. Drug Discovery Today: Disease Models, 2014(In press).

70. Hermsen, R., J.B. Deris, and T. Hwa, On the rapidity of antibiotic resistance evolution facilitated by a concentration gradient. Proc Natl Acad Sci U S A, 2012. 109(27): p. 10775-80.

71. Zhang, Q., et al., Acceleration of emergence of bacterial antibiotic resistance in connected microenvironments. Science, 2011. 333(6050): p. 1764-7.

72. Srivastava, S., et al., Multidrug-resistant tuberculosis not due to noncompliance but to between-patient pharmacokinetic variability. J Infect Dis, 2011. 204(12): p. 1951-9.

73. Loos, U., et al., Pharmacokinetics of oral and intravenous rifampicin during chronic administration. Klin Wochenschr, 1985. 63(23): p. 1205-11.

74. Mahapatra, S., et al., A novel metabolite of antituberculosis therapy demonstrates host activation of isoniazid and formation of the isoniazid-NAD+ adduct. Antimicrob Agents Chemother, 2012. 56(1): p. 28-35.

75. Pruijn, F.B., et al., Prediction of Tumour Tissue Diffusion Coefficients of Hypoxia-Activated Prodrugs from Physicochemical Parameters. Australian Journal of Chemistry, 2008. 61(9): p. 687-693.

76. Jeena, P.M., et al., In silico children and the glass mouse model: clinical trial simulations to identify and individualize optimal isoniazid doses in children with tuberculosis. Antimicrob Agents Chemother, 2011. 55(2): p. 539-45.

77. Mor, N., et al., Comparison of activities of rifapentine and rifampin against Mycobacterium tuberculosis residing in human macrophages. Antimicrob Agents Chemother, 1995. 39(9): p. 2073-7.

78. Forsgren, A. and A. Bellahsene, Antibiotic accumulation in human polymorphonuclear leucocytes and lymphocytes. Scand J Infect Dis Suppl, 1985. 44: p. 16-23.

79. Ziglam, H.M., et al., Rifampicin concentrations in bronchial mucosa, epithelial lining fluid, alveolar macrophages and serum following a single $600 \mathrm{mg}$ oral dose in patients undergoing fibre-optic bronchoscopy. J Antimicrob Chemother, 2002. 50(6): p. 1011-5.

80. Schmidt, M.M. and K.D. Wittrup, A modeling analysis of the effects of molecular size and binding affinity on tumor targeting. Mol Cancer Ther, 2009. 8(10): p. 2861-71. 
Table 1: Key features identified by analysis to drive bacterial clearance/non-

clearance, CFU after treatment, or time to clearance. See Supplement for details.

\begin{tabular}{|c|c|c|c|}
\hline & Host features & $\begin{array}{l}\text { Bacterial } \\
\text { features }\end{array}$ & Antibiotics features \\
\hline $\begin{array}{l}\text { Pre-treatment } \\
\text { (100 d.p.i) }\end{array}$ & $\begin{array}{c}\text { TNF induced } \\
\text { apoptosis }^{1 *} \\
\text { Granuloma size }^{1} \\
\text { Caseation }^{1} \\
\text { Macrophage } \\
\text { activation }^{1 *} \\
\text { Tcell activation }^{1} \\
\text { Tcell-mediated } \\
\text { killing } \\
\text { Cell recruitment }\end{array}$ & $\begin{array}{c}\text { Intracellular CFU1 } \\
\text { Non-replicating } \\
\text { extracellular CFU' } \\
\text { Time spent } \\
\text { intracellular }^{1}\end{array}$ & $\mathrm{~N} / \mathrm{A}$ \\
\hline $\begin{array}{l}\text { During } \\
\text { treatment } \\
(100 \text { to } 280 \\
\text { d.p.i) }\end{array}$ & $\begin{array}{c}\text { Resting } \\
\text { macrophage killing } \\
\text { of Mtb }{ }^{2} \\
\text { Tcell-mediated } \\
\text { killing }{ }^{2} \\
\text { TNF induced } \\
\text { apoptosis }{ }^{2 * \#} \\
\text { Caseation }{ }^{2 \#} \\
\text { Macrophage } \\
\text { activation }^{2 * \#} \\
\text { Cell movement and } \\
\text { recruitment }{ }^{* * \#}\end{array}$ & $\begin{array}{l}\text { Time spent } \\
\text { intracellular }\end{array}$ & $\begin{array}{c}\text { AUC }^{1} \\
\text { Plasma clearance } \\
\text { rate }^{3,4} \\
\text { Intercompartmental } \\
\text { clearance } \\
\text { Intracellular antibiotic } \\
\text { degradation }^{3,4} \\
\text { Vascular }^{4} \\
\text { permeability } \\
\text { Diffusivity } \\
\text { Cellular accumulation } \\
\text { ratio }^{3} \\
\text { Hill constant } \\
\text { Max activity }^{3} \\
C_{50} \text { intracellular }^{3} \\
\end{array}$ \\
\hline \multicolumn{4}{|c|}{$\begin{array}{c}\text { 1: Bayes classification; }{ }^{2} \text { : Host PRCC; }{ }^{3} \text { : Antibiotic PRCC; }{ }^{4} \text { : eFAST } \\
\text { *: Also identified as significant in [35] } \\
\text { \#: Significant in treated and untreated granulomas } \\
\text { Note: parameters are grouped for the sake of clarity and groups are defined in the } \\
\text { Supplement }\end{array}$} \\
\hline
\end{tabular}




\section{Figure legends}

Figure 1: Model structure. (A) Tissue pharmacokinetics (PK) are added to the existing granuloma model (GranSim) by accounting for antibiotic permeability through vascular walls, diffusion in tissue, uptake by host cells, and degradation by host cells and bacteria. (B) Plasma PK is modeled using two transit compartments, a plasma compartment and a peripheral compartment. The peripheral compartment represents other tissues and organs. Antibiotic doses are added to the first transit compartment. Antibiotic dynamics in the plasma compartment are characterized using the metrics indicated in the bottom panel. (C) Pharmacodynamics are implemented using $E_{\max }$ models, defined by maximum activity ( $\left.E_{\max }\right)$, concentration where $50 \%$ of maximum activity is achieved $\left(C_{50}\right)$, and Hill constant $(H)$ describing steepness of the curve. We define PD parameters separately for bacterial subpopulations, since different subpopulations have been shown to have different susceptibilities to INH and RIF[르, $\underline{38}, \underline{39}]$. We define Emax and $C_{50}$ for each antibiotic and bacterial subpopulation combination. $k_{a}$ : absorption rate constant; $Q$ : inter-compartmental clearance rate constant; $C L$ : clearance rate constant from plasma; $C_{p}$ : plasma antibiotic concentration; $C_{\text {max }}$ : maximum concentration; AUC: area under the curve; $t_{\max }$ : time after dosing when maximal concentration is reached; MIC: minimum inhibitory concentration.

Figure 2: Computational model calibration. Our model is calibrated to PK and PD data from rabbits and NHPs for both INH and RIF. (A) Three plasma PK outputs 
from the model (black bars) match values measured in NHPs (white bars). Bars show means, and error bars show SD (For model fit: N=100; for NHP: N=7). See Appendix E for parameter ranges used to give variation in model outcomes. (B) Tissue PK parameters are fit (black bars) to give tissue: plasma AUC ratios similar to those measured in rabbit granulomas (white bars). For normal lung, the model fit results from uninfected simulations $(\mathrm{N}=5)$. For granuloma values, the model fit measurements are from inside the circumference of granulomas $(\mathrm{N}=5)$. Bars show means and error bars show SD. (C) PD parameters are fit (filled circles) to match CFU per granuloma measurements from NHPs (open circles) at 160 d.p.i. The percentages of granulomas that clear all bacteria are listed. Red lines show median CFU for granulomas that do not clear in both experiments and simulations. If granulomas that clear are included, it skews the medians toward zero, biasing the fit (not shown).

Figure 3: Average bacterial and antibiotic dynamics in granulomas. INH (A) and RIF (B) concentrations inside granulomas are plotted on left y-axes; bacterial subpopulations are plotted on right y-axes. Colored solid lines are mean and colored dashed lines are $+/$ - SEM $(\mathrm{N}=412)$. Black lines are $C_{50}$ values for intracellular $\left(C_{50, B I}\right)$, extracellular $\left(C_{50, B E}\right)$ and non-replicating $\left(C_{50, B N}\right)$ bacterial populations.

Figure 4: Changes in bacterial subpopulations over time. Panels A and B show total CFU per granuloma (mean +/-SEM) for cleared and non-cleared granulomas during INH (A) and RIF (B) treatment. INH cleared: N=362; RIF cleared: N=385; INH not 
cleared: $N=50$; RIF not cleared: $N=27$. Panels $C$ and $D$ show relative proportions of each bacterial subpopulation (intracellular, extracellular and non-replicating extracellular). The onset of adaptive immunity ( $\sim 28$ d.p.i.) and treatment at 100 d.p.i. are marked. Lines indicate means +/- SEM (N=412) for INH (C) and RIF (D).

Figure 5: Snapshots of two representative simulated granulomas. Panels 1,2,4 and 6 show cells in the granuloma: resting macrophages (green), infected macrophages (orange); chronically infected macrophages (red), caseation (white), activated macrophages (blue). A few T cells comprise the lymphocyte cuff around the outside of the macrophages (purple, pink and light blue). There are a few extracellular Mtb (brown). Each granuloma is shown before treatment at 100 d.p.i. (panels A1 and B1) and at 160 d.p.i. when untreated (panels A2 and B2). Panels A4 and B4 show the granulomas after 60 days of daily INH treatment $(15 \mathrm{mg} / \mathrm{kg}$ ) and panels A6 and B6 show the granulomas after 60 days of daily RIF treatment (20 mg/kg). Panels 3 and 5 show cumulative INH and RIF exposure respectively (AUC in mg.h/L) as a function of position within the granuloma during the first week of treatment. Color bars are scaled from $0 \mathrm{mg} . \mathrm{h} / \mathrm{L}$ to the AUC EC80 (exposure where $80 \%$ of maximum efficiency is achieved) for each antibiotic (3 mg.h/L for INH and $200 \mathrm{mg} . \mathrm{h} / \mathrm{L}$ for RIF). Timelapse movies of drug distribution and treatment progression, and high-resolution images that better show cellular level details (such as T-cells and caseation) are available at http://malthus.micro.med.umich.edu/lab/movies/Abx/. 
Figure 6: Average antibiotic exposure in granulomas. Spatial AUC is averaged for all grid compartments inside the boundary of the granuloma during the first day of treatment and plotted for each granuloma treated with INH (left y-axis) and RIF (right y-axis). Data points represent individual granulomas, bars and error bars represent mean $+/-\mathrm{SD}(\mathrm{N}=412)$. 


\section{Appendix A -GranSim parameters}

Baseline parameter set derived from fitting to NHP CFU data for a 200x200 grid, and ranges used for host-specific PRCC.

\begin{tabular}{|l|l|l|l|l|}
\hline & & \multicolumn{2}{|c|}{ Ranges for Host- } \\
\hline Parameter & Unit* & $\begin{array}{l}\text { Baseline } \\
\text { Value }\end{array}$ & Min & Max \\
\hline $\begin{array}{l}\text { Bacterial carrying capacity } \\
\text { of each grid compartment }\end{array}$ & Bacteria & 115 & & \\
\hline $\begin{array}{l}\text { Intracellular bacterial } \\
\text { growth rate }\end{array}$ & $\mathrm{h}^{-1}$ & 0.027 & & \\
\hline $\begin{array}{l}\text { Extracellular bacterial } \\
\text { growth rate }\end{array}$ & $\mathrm{h}^{-1}$ & 0.015 & & \\
\hline $\begin{array}{l}\text { Rate of death of bacteria } \\
\text { trapped in caseated } \\
\text { compartments }\end{array}$ & $\mathrm{h}^{-1}$ & 5.1 & & 11 \\
\hline $\begin{array}{l}\text { Number of host cell deaths } \\
\text { causing caseation }\end{array}$ & & 9 & 7 & 12 \\
\hline Time to heal caseation \\
\hline $\begin{array}{l}\text { TNF threshold for causing } \\
\text { apoptosis }\end{array}$ & Molecules & 1150 & 920 & 1380 \\
\hline $\begin{array}{l}\text { Rate of TNF induced } \\
\text { apoptosis }\end{array}$ & $\mathrm{s}^{-1}$ & $1.7 \times 10-6$ & $1.3 \times 10-6$ & $2.04 \times 10-6$ \\
\hline $\begin{array}{l}\text { Minimum chemokine } \\
\text { concentration allowing } \\
\text { chemotaxis }\end{array}$ & Molecules & 0.47 & 0.4 & 0.6 \\
\hline $\begin{array}{l}\text { Maximum chemokine } \\
\text { concentration allowing } \\
\text { chemotaxis }\end{array}$ & Molecules & 480 & 380 & 570 \\
\hline $\begin{array}{l}\text { Initial macrophage density } \\
\text { Fraction of grid } \\
\text { comp. }\end{array}$ & 0.04 & 0.03 & 0.05 \\
\hline $\begin{array}{l}\text { Time steps before a resting } \\
\text { macrophage can move }\end{array}$ & Timesteps & 3 & 2.4 & 3.6 \\
\hline $\begin{array}{l}\text { Time steps before an } \\
\text { activated macrophage can } \\
\text { move }\end{array}$ & Timesteps & 19 & 15 & 23 \\
\hline $\begin{array}{l}\text { Time steps before an } \\
\text { infected macrophage can } \\
\text { move }\end{array}$ & Timesteps & 170 & 135 & 200 \\
\hline $\begin{array}{l}\text { TNF threshold for } \\
\text { activating NFkB }\end{array}$ & Molecules & 75 & 60 & 90 \\
\hline Rate of TNF induced NFkB & $\mathrm{s}^{-1}$ & $1.06 \times 10-5$ & $8.5 \times 10-6$ & $1.3 \times 10-5$ \\
\hline
\end{tabular}




\begin{tabular}{|c|c|c|c|c|}
\hline activation & & & & \\
\hline $\begin{array}{l}\text { Number of bacteria resting } \\
\text { macrophage can } \\
\text { phagocytose }\end{array}$ & Bacteria & 1 & & \\
\hline $\begin{array}{l}\text { Probability of resting } \\
\text { macrophage killing } \\
\text { bacteria }\end{array}$ & & 0.12 & 0.1 & 0.15 \\
\hline $\begin{array}{l}\text { Adjustment for killing } \\
\text { probability of resting } \\
\text { macrophages with NFkB } \\
\text { activated }\end{array}$ & & 0.2 & 0.15 & 0.25 \\
\hline $\begin{array}{l}\text { Number of extracellular } \\
\text { bacteria that can activate } \\
\text { NFkB }\end{array}$ & Bacteria & 250 & 200 & 300 \\
\hline $\begin{array}{l}\text { Threshold for intracellular } \\
\text { bacteria causing } \\
\text { chronically infected } \\
\text { macrophages }\end{array}$ & Bacteria & 12 & 10 & 15 \\
\hline $\begin{array}{l}\text { Threshold for intracellular } \\
\text { bacteria causing } \\
\text { macrophage to burst }\end{array}$ & Bacteria & 23 & 18 & 30 \\
\hline $\begin{array}{l}\text { Number of bacteria } \\
\text { activated macrophage can } \\
\text { phagocytose }\end{array}$ & Bacteria & 5 & 4 & 6 \\
\hline $\begin{array}{l}\text { Probability of an activated } \\
\text { macrophage healing a } \\
\text { caseated compartment in } \\
\text { its Moore neighborhood }\end{array}$ & & 0.0055 & 0.0044 & 0.0066 \\
\hline $\begin{array}{l}\text { Probability of a T-cell } \\
\text { moving to the same } \\
\text { compartment as a } \\
\text { macrophage }\end{array}$ & & 0.046 & 0.035 & 0.055 \\
\hline $\begin{array}{l}\text { IFN } \gamma \text {-producing T-cell } \\
\text { probability of inducing } \\
\text { Fas/FasL mediated } \\
\text { apoptosis }\end{array}$ & & 0.035 & 0.03 & 0.04 \\
\hline $\begin{array}{l}\text { IFN } \gamma \text {-producing T-cell } \\
\text { probability of producing } \\
\text { TNF }\end{array}$ & & 0.045 & 0.04 & 0.05 \\
\hline $\begin{array}{l}\text { IFN } \gamma \text {-producing T-cell } \\
\text { probability of producing } \\
\text { IFN }\end{array}$ & & 0.35 & 0.3 & 0.45 \\
\hline $\begin{array}{l}\text { Cytotoxic T-cell probability } \\
\text { of killing a macrophage }\end{array}$ & & 0.009 & 0.007 & 0.010 \\
\hline Cytotoxic T-cell probability & & 0.7 & 0.6 & 0.9 \\
\hline
\end{tabular}




\begin{tabular}{|c|c|c|c|c|}
\hline $\begin{array}{l}\text { of killing a macrophage } \\
\text { and all of its intracellular } \\
\text { bacteria }\end{array}$ & & & & \\
\hline $\begin{array}{l}\text { Cytotoxic T-cell probability } \\
\text { of producing TNF }\end{array}$ & & 0.05 & 0.04 & 0.06 \\
\hline $\begin{array}{l}\text { Regulatory T-cell } \\
\text { probability of deactivating } \\
\text { activated macrophage }\end{array}$ & & 0.008 & 0.006 & 0.01 \\
\hline $\begin{array}{l}\text { Time before maximum } \\
\text { recruitment rates are } \\
\text { reached }\end{array}$ & Timesteps & 980 & 790 & 1180 \\
\hline $\begin{array}{l}\text { Macrophage maximal } \\
\text { recruitment probability }\end{array}$ & & 0.32 & 0.25 & 0.4 \\
\hline $\begin{array}{l}\text { Macrophage chemokine } \\
\text { recruitment threshold }\end{array}$ & Molecules & 0.86 & 0.7 & 1 \\
\hline $\begin{array}{l}\text { Macrophage TNF } \\
\text { recruitment threshold }\end{array}$ & Molecules & 0.011 & 0.009 & 0.015 \\
\hline $\begin{array}{l}\text { Macrophage half sat for } \\
\text { TNF recruitment }\end{array}$ & Molecules & 1.6 & 1.3 & 2 \\
\hline $\begin{array}{l}\text { Macrophage half sat for } \\
\text { chemokine recruitment }\end{array}$ & Molecules & 2.2 & 1.8 & 2.6 \\
\hline $\begin{array}{l}\text { IFN } \gamma \text {-producing T-cell } \\
\text { maximal recruitment } \\
\text { probability }\end{array}$ & & 0.15 & 0.12 & 0.18 \\
\hline $\begin{array}{l}\text { IFN } \gamma \text {-producing T-cell } \\
\text { chemokine recruitment } \\
\text { threshold }\end{array}$ & Molecules & 0.07 & 0.06 & 0.09 \\
\hline $\begin{array}{l}\text { IFN } \gamma \text {-producing T-cell } \\
\text { TNF recruitment threshold }\end{array}$ & Molecules & 1.3 & 1 & 1.6 \\
\hline $\begin{array}{l}\text { IFN } \gamma \text {-producing T-cell } \\
\text { half sat for TNF } \\
\text { recruitment }\end{array}$ & Molecules & 1.3 & 1 & 1.6 \\
\hline $\begin{array}{l}\text { IFN } \gamma \text {-producing T-cell } \\
\text { half sat for chemokine } \\
\text { recruitment }\end{array}$ & Molecules & 2 & 1.5 & 2.5 \\
\hline $\begin{array}{l}\text { Cytotoxic T-cell maximal } \\
\text { recruitment probability }\end{array}$ & & 0.12 & 0.1 & 0.15 \\
\hline $\begin{array}{l}\text { Cytotoxic T-cell chemokine } \\
\text { recruitment threshold }\end{array}$ & Molecules & 4.5 & 3.6 & 5.4 \\
\hline $\begin{array}{l}\text { Cytotoxic T-cell TNF } \\
\text { recruitment threshold }\end{array}$ & Molecules & 1.3 & 1 & 1.5 \\
\hline $\begin{array}{l}\text { Cytotoxic T-cell half sat for } \\
\text { TNF recruitment }\end{array}$ & Molecules & 1.2 & 1 & 1.5 \\
\hline $\begin{array}{l}\text { Cytotoxic T-cell half sat for } \\
\text { chemokine recruitment }\end{array}$ & Molecules & 9 & 7 & 10 \\
\hline
\end{tabular}




\begin{tabular}{|l|l|l|l|l|}
\hline $\begin{array}{l}\text { Regulatory T-cell maximal } \\
\text { recruitment probability }\end{array}$ & 0.03 & 0.02 & 0.04 \\
\hline $\begin{array}{l}\text { Regulatory T-cell } \\
\text { chemokine recruitment } \\
\text { threshold }\end{array}$ & Molecules & 2 & 1.5 & 2.5 \\
\hline $\begin{array}{l}\text { Regulatory T-cell TNF } \\
\text { recruitment threshold }\end{array}$ & Molecules & 1.7 & 1.3 & 2 \\
\hline $\begin{array}{l}\text { Regulatory T-cell half sat } \\
\text { for TNF recruitment }\end{array}$ & Molecules & 2.2 & 1.8 & 2.7 \\
\hline $\begin{array}{l}\text { Regulatory T-cell half sat } \\
\text { for chemokine recruitment }\end{array}$ & Molecules & 1.5 & 1.2 & 1.8 \\
\hline
\end{tabular}

*Conversion factor: $10 \mathrm{~min} /$ timestep.

\section{Appendix B - Plasma PK model equations}

Equations describing plasma PK are taken from [15]:

$$
\begin{gathered}
\frac{d C_{t 1}}{d t}=-k_{a} C_{t 1} \\
\frac{d C_{t 2}}{d t}=k_{a}\left(C_{t 1}-C_{t 2}\right) \\
\frac{d C_{P e}}{d t}=Q\left(C_{P} / V_{P}-C_{P e} / V_{P e}\right) \\
\frac{d C_{P}}{d t}=k_{a} C_{t 2}-Q\left(C_{P} / V_{P}-C_{P e} / V_{P e}\right)-C L C_{P} / V_{P}
\end{gathered}
$$

$C_{t 1}$ and $C_{t 2}$ are concentrations of antibiotic in first and second transit compartments, and $C_{P e}$ and $C_{P}$ are concentrations in peripheral and plasma compartments $(\mathrm{mg} / \mathrm{kg}) . V_{P e}$ and $V_{P}$ are volumes of distribution for peripheral and plasma compartments (L/kg). $k_{a}$ is the absorption rate constant $\left(\mathrm{h}^{-1}\right), Q$ is the intercompartmental clearance rate constant between the plasma and peripheral compartments $(\mathrm{L} / \mathrm{h} / \mathrm{kg})$ and $C L$ is the clearance rate constant from the plasma compartment $(\mathrm{L} / \mathrm{h} / \mathrm{kg})$.

\section{Appendix C - Tissue PK model antibiotic degradation}

Antibiotics are assumed to degrade according to

$$
\frac{d C_{x}}{d t}=-k_{d e g, x} C_{x}
$$


where $k_{d e g, x}$ is the degradation rate constant, and $C_{x}$ is the intracellular or extracellular antibiotic concentration[45, 74]. Antibiotic degradation in tissue is minimal compared to losses by leaking back into plasma.

\section{Appendix D - PD model equations}

The rate constants $\left(k_{k i l, x}\right)$ describing antibiotic killing of bacteria are calculated for based on the bacterial subpopulation (intracellular, replicating extracellular or nonreplicating extracellular) and local antibiotic concentrations (intra- or extracellular) according to [Error! Hyperlink reference not valid.]:

$$
k_{\text {kill }, x}=E_{\max }^{x} \frac{C_{x}^{H}}{C_{x}^{H}+C_{50, x}^{H}}
$$

where $x$ denotes the bacterial sub-population (intracellular, extracellular replicating or extracellular non-replicating), $C$ is local antibiotic concentration, $E_{\max }$ is maximum activity, $C_{50}$ is concentration where $50 \%$ of maximum activity is achieved, and $H$ is the Hill constant describing steepness of the curve. 


\section{Appendix E - PK and PD parameters}

Baseline parameter set derived from fitting to NHP and rabbit data, and ranges used for antibiotic-specific PRCC.

\begin{tabular}{|c|c|c|c|c|c|}
\hline Parameter Name & Units & INH & RIF & $\begin{array}{l}\text { Ranges used for } \\
\text { antibiotic- } \\
\text { specific PRCC }\end{array}$ & Reference \\
\hline \multicolumn{6}{|l|}{ Plasma PK parameters (1) } \\
\hline $\begin{array}{l}\text { Absorption rate constant } \\
\left(k_{a}\right)\end{array}$ & $\mathrm{h}^{-1}$ & $1-5$ & $0.2-0.8$ & $0.1-10$ & $\begin{array}{l}\text { Fit to data in } \\
\text { [18] guided } \\
\text { by values in } \\
{[15,57,58]}\end{array}$ \\
\hline $\begin{array}{l}\text { Intercompartmental } \\
\text { clearance rate constant }(Q)\end{array}$ & $\mathrm{L} / \mathrm{h} / \mathrm{kg}$ & $0.025-0.2$ & $0.1-0.7$ & $0.01-1$ & $\begin{array}{l}\text { Fit to data in } \\
\text { [18] guided } \\
\text { by values in } \\
{[15,57,58]}\end{array}$ \\
\hline $\begin{array}{l}\text { Plasma volume of } \\
\text { distribution }\left(V_{p}\right)\end{array}$ & $\mathrm{L} / \mathrm{kg}$ & $0.1-2$ & $0.5-1.5$ & $0.05-5$ & $\begin{array}{l}\text { Fit to data in } \\
\text { [18] guided } \\
\text { by values in } \\
{[15,57,58]}\end{array}$ \\
\hline $\begin{array}{l}\text { Peripheral volume of } \\
\text { distribution (other organs } \\
\text { and tissues) }\left(V_{p e}\right)\end{array}$ & $\mathrm{L} / \mathrm{kg}$ & $20-40$ & $0.1-1$ & $0.1-50$ & $\begin{array}{l}\text { Fit to data in } \\
\text { [18] guided } \\
\text { by values in } \\
{[15,57,58]}\end{array}$ \\
\hline $\begin{array}{l}\text { Plasma clearance rate } \\
\text { constant }(C L)\end{array}$ & $\mathrm{L} / \mathrm{h} / \mathrm{kg}$ & $0.6-1.8$ & $0.25-0.5$ & $0.05-5$ & $\begin{array}{l}\text { Fit to data in } \\
\text { [18] guided } \\
\text { by values in } \\
{[15,57,58]}\end{array}$ \\
\hline \multicolumn{6}{|l|}{$\begin{array}{l}\text { Lung tissue PK } \\
\text { parameters }\end{array}$} \\
\hline $\begin{array}{l}\text { Degradation rate constant, } \\
\text { extracellular }\left(K_{\text {deg,e }}\right)\end{array}$ & $\mathrm{s}^{-1}$ & $\begin{array}{l}5.5^{*} 10^{\wedge}- \\
9\end{array}$ & $7.5^{*} 10^{\wedge}-8$ & $1^{*} 10^{\wedge}-9-1 * 10^{\wedge}-7$ & $\begin{array}{l}\text { Fit to data in } \\
\text { [15] }\end{array}$ \\
\hline $\begin{array}{l}\text { Degradation rate constant, } \\
\text { intracellular }\left(K_{\text {deg }, i}\right)\end{array}$ & $\mathrm{s}^{-1}$ & $\begin{array}{l}6.4^{*} 10^{\wedge}- \\
3\end{array}$ & $6.7^{*} 10^{\wedge}-3$ & $5^{*} 10^{\wedge}-4-5^{*} 10^{\wedge}-2$ & $\begin{array}{l}\text { Fit to data in } \\
\text { [15] }\end{array}$ \\
\hline Effective diffusivity $(D)$ & $\mathrm{cm}^{2} / \mathrm{s}$ & $\begin{array}{l}1.1^{*} 10^{\wedge}- \\
7\end{array}$ & $7 * 10^{\wedge}-7$ & $1 * 10^{\wedge}-8-1 * 10^{\wedge}-6$ & $\begin{array}{l}\text { Fit to data in } \\
\text { [15] guided } \\
\text { by values in }\end{array}$ \\
\hline
\end{tabular}




\begin{tabular}{|c|c|c|c|c|c|}
\hline & & & & & [75] \\
\hline $\begin{array}{l}\text { Cellular accumulation ratio } \\
\text { (2) }(a)\end{array}$ & - & 0.35 & 18 & $0.2-20$ & $\begin{array}{l}\text { Fit to data in } \\
\text { [15] guided } \\
\text { by values in } \\
\text { [76-79] }\end{array}$ \\
\hline Vascular permeability $(p)$ & $\mathrm{cm} / \mathrm{s}$ & $\begin{array}{l}8.4^{*} 10^{\wedge}- \\
6\end{array}$ & $1 * 10^{\wedge}-5$ & $1^{*} 10^{\wedge}-6-1^{*} 10^{\wedge}-4$ & $\begin{array}{l}\text { Fit to data in } \\
\text { [15] guided } \\
\text { by values in } \\
\text { [80] }\end{array}$ \\
\hline $\begin{array}{l}\text { Permeability coefficient } \\
(P C)\end{array}$ & - & 0.25 & 3.3 & $0.1-10$ & [15] \\
\hline \multicolumn{6}{|l|}{ PD parameters } \\
\hline $\begin{array}{l}\text { C50 for intracellular Mtb } \\
\left(C_{50, B I}\right)\end{array}$ & $\mathrm{mg} / \mathrm{L}$ & 0.02 & 10 & $0.01-10$ & $\begin{array}{l}{[23,38,39,} \\
59]\end{array}$ \\
\hline $\begin{array}{l}\text { C50 for extracellular } \\
\text { replicating Mtb }\left(\mathrm{C}_{50, B E}\right)\end{array}$ & $\mathrm{mg} / \mathrm{L}$ & 0.04 & 1.23 & $0.01-10$ & $\begin{array}{l}{[23,38,39,} \\
59]\end{array}$ \\
\hline $\begin{array}{l}\text { C50 for extracellular non- } \\
\text { replicating Mtb }\left(C_{50, B N}\right)\end{array}$ & $\mathrm{mg} / \mathrm{L}$ & 0.5 & 5 & $0.01-10$ & $\begin{array}{l}{[23,38,39,} \\
59]\end{array}$ \\
\hline $\begin{array}{l}\text { Hill constant for } \\
\text { intracellular Mtb }\left(H_{B I}\right)\end{array}$ & - & 1 & 0.48 & $0.1-2$ & $\begin{array}{l}{[23,38,39,} \\
59]\end{array}$ \\
\hline $\begin{array}{l}\text { Hill constant for } \\
\text { extracellular replicating Mtb } \\
\left(H_{B E}\right)\end{array}$ & - & 1 & 0.7 & $0.1-2$ & $\begin{array}{l}{[23,38,39,} \\
59]\end{array}$ \\
\hline $\begin{array}{l}\text { Hill constant for } \\
\text { extracellular non- } \\
\text { replicating Mtb }\left(H_{B N}\right)\end{array}$ & - & 1 & 0.7 & $0.1-2$ & $\begin{array}{l}\text { Assumed } \\
\text { same as } \\
\text { extracellular } \\
\text { replicating }\end{array}$ \\
\hline $\begin{array}{l}\text { Max activity intracellular } \\
\left(E_{\max , B I}\right)\end{array}$ & $\mathrm{s}^{1}$ & $\begin{array}{l}7.7^{*} 10^{\wedge}- \\
5\end{array}$ & $1.1^{*} 10^{\wedge}-4$ & $\begin{array}{l}1.7^{*} 10^{\wedge}-5- \\
1.5^{*} 10^{\wedge}-3\end{array}$ & $\begin{array}{l}\text { Fit to data in } \\
\text { [4] guided } \\
\text { by values in } \\
{[38,39]}\end{array}$ \\
\hline $\begin{array}{l}\text { Max activity extracellular } \\
\left(E_{\max , B E}\right)\end{array}$ & $\mathrm{s}^{-1}$ & $2.6 * 10-4$ & $5^{*} 10^{\wedge}-4$ & $\begin{array}{l}1.7^{*} 10^{\wedge}-5- \\
1.5^{*} 10^{\wedge}-3\end{array}$ & $\begin{array}{l}\text { Fit to data in } \\
\text { [4] guided } \\
\text { by values in } \\
{[38,39]}\end{array}$ \\
\hline \multicolumn{6}{|c|}{ (1): Plasma PK parameters are given a range of values to account for inter-individual variation } \\
\hline
\end{tabular}




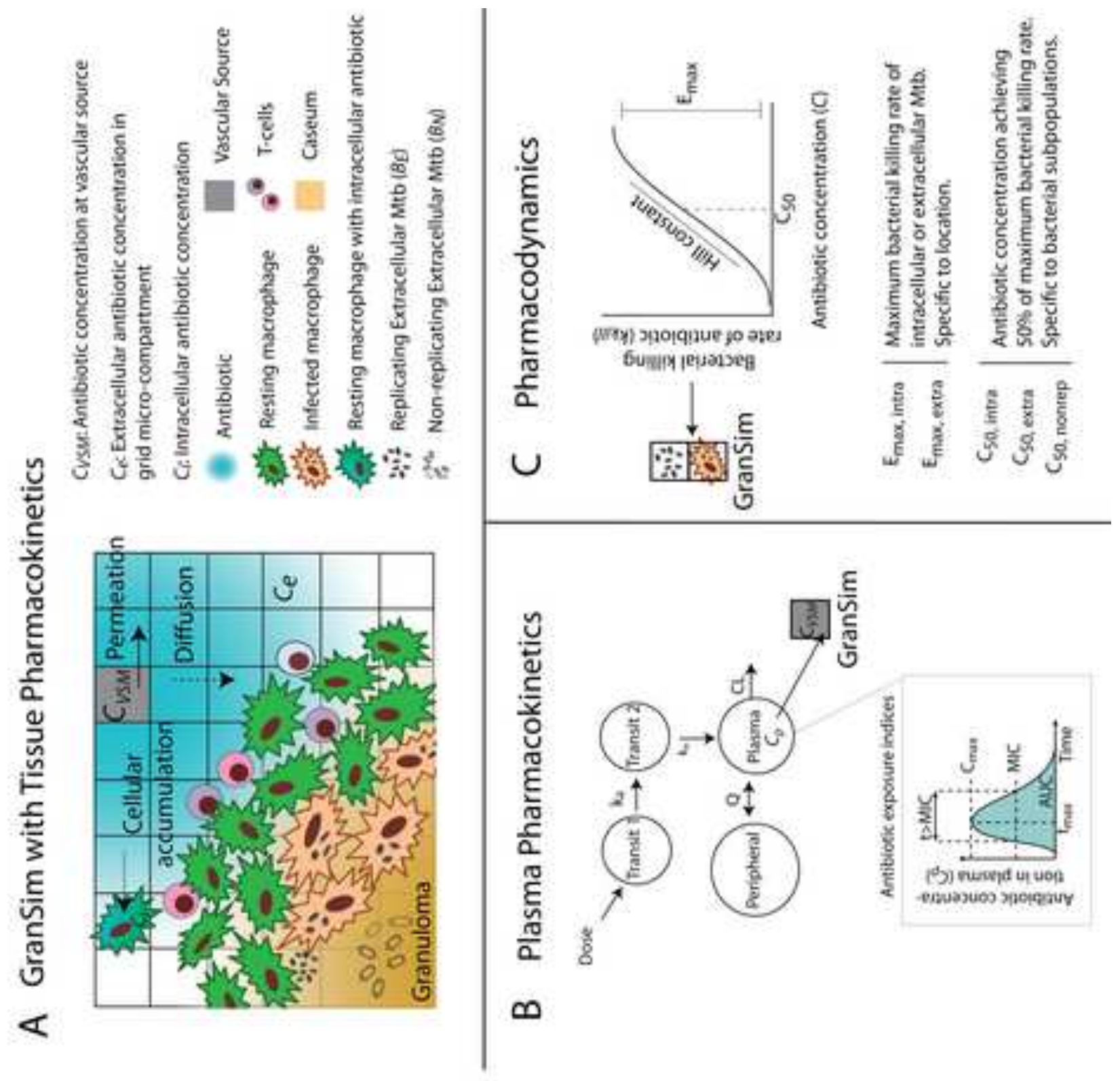


INH
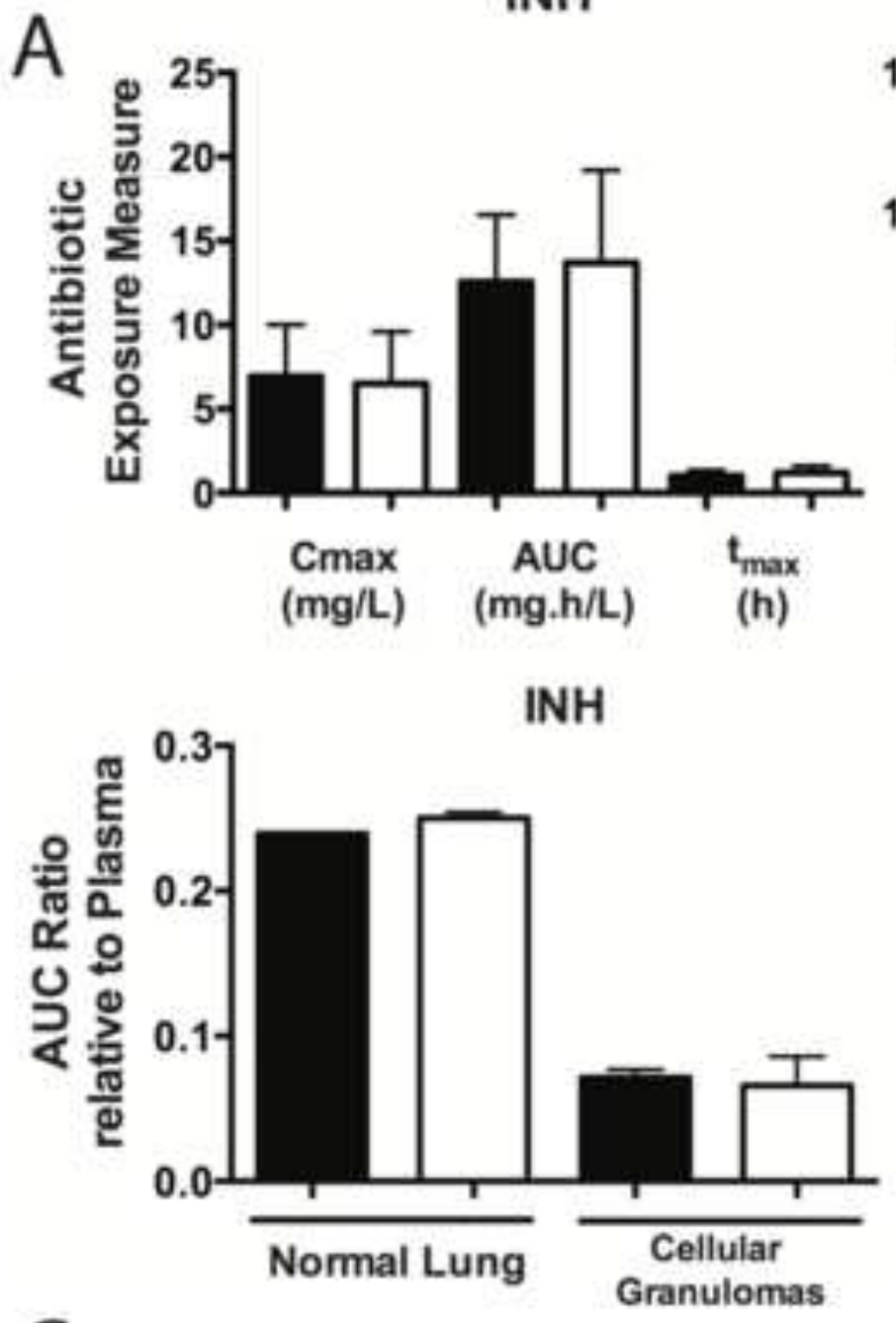

\section{RIF}
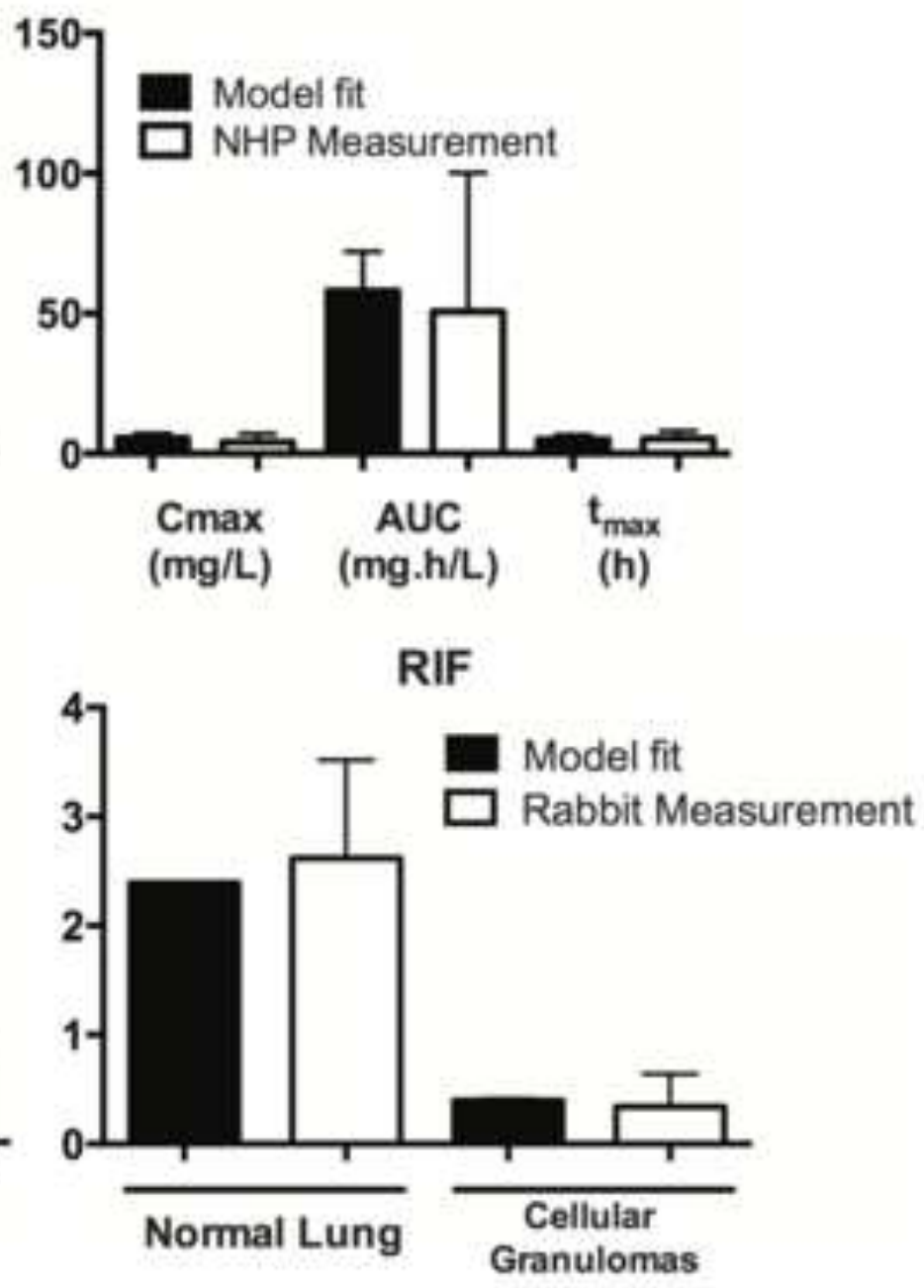

- Model fit

- NHP Measurement
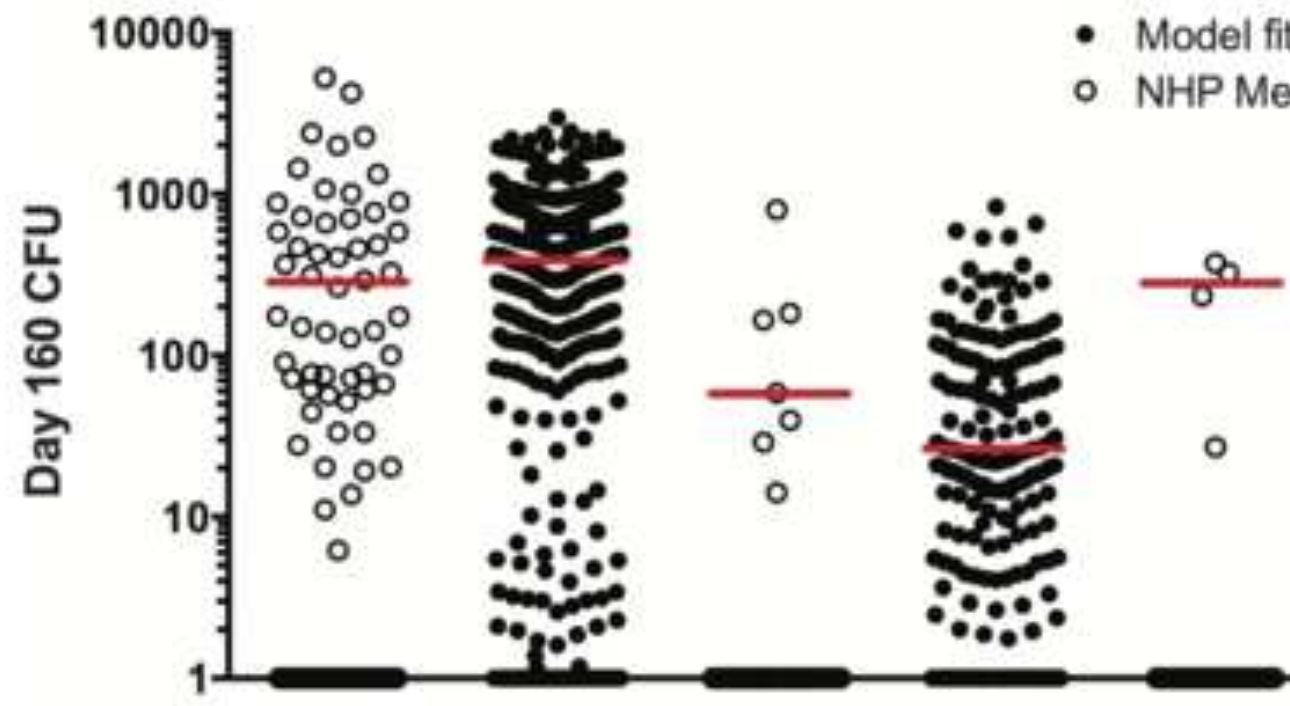

$\%$ cleared

\begin{tabular}{cc}
$\begin{array}{c}41 \\
(N=99)\end{array} \quad \begin{array}{c}20 \\
(N=500\end{array}$ \\
\hline Untreated
\end{tabular}

20

82

$(\mathrm{N}=42)$

69

$(\mathrm{N}=500)$

89

$(\mathrm{N}=37)$

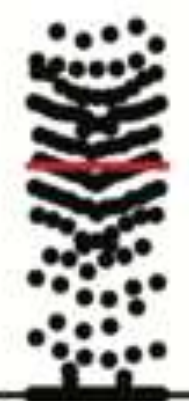

74

$(\mathrm{N}=500)$

INH 
A

INH 7 doses per week

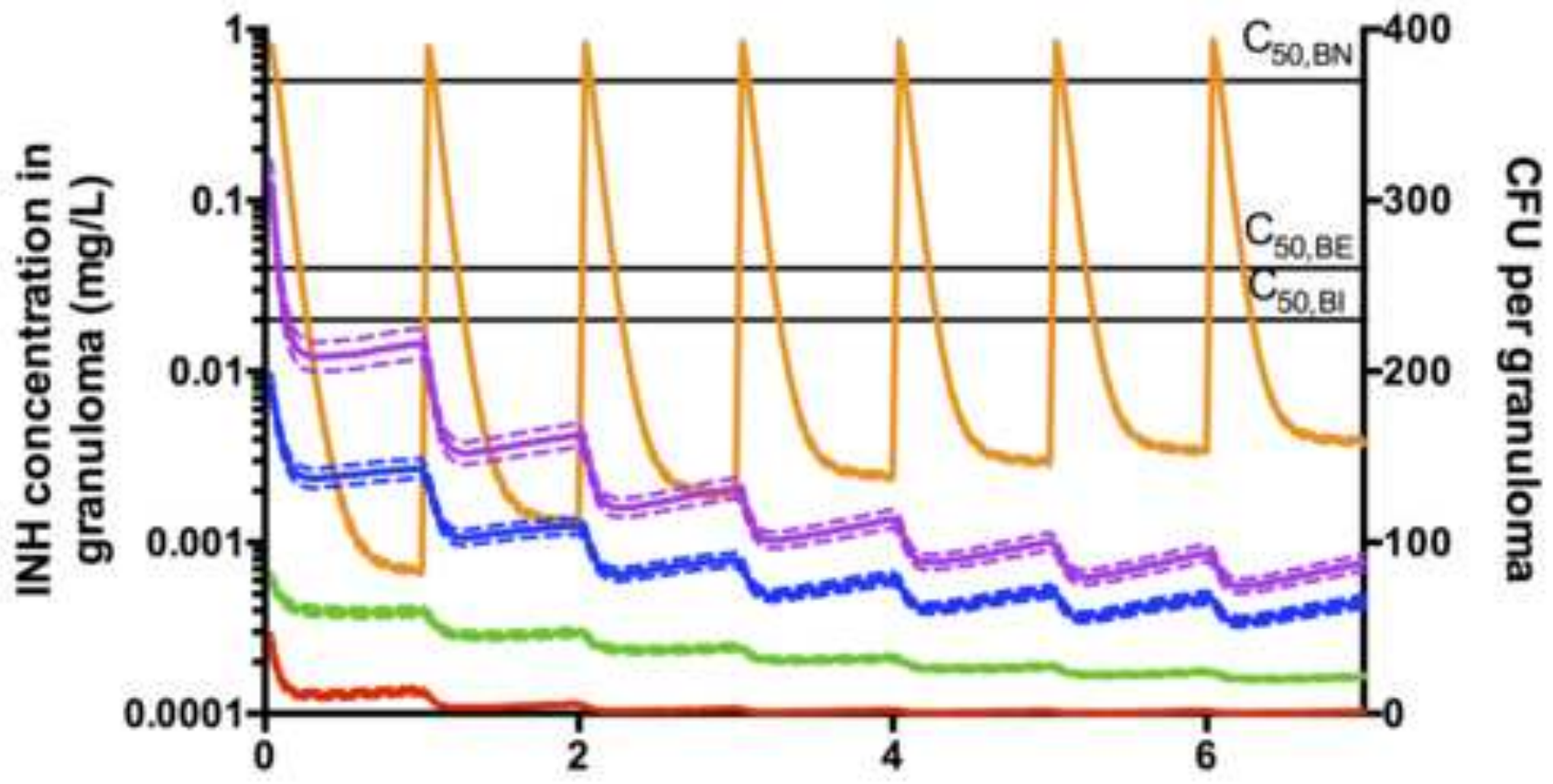

Days post treatment start

RIF 7 doses per week

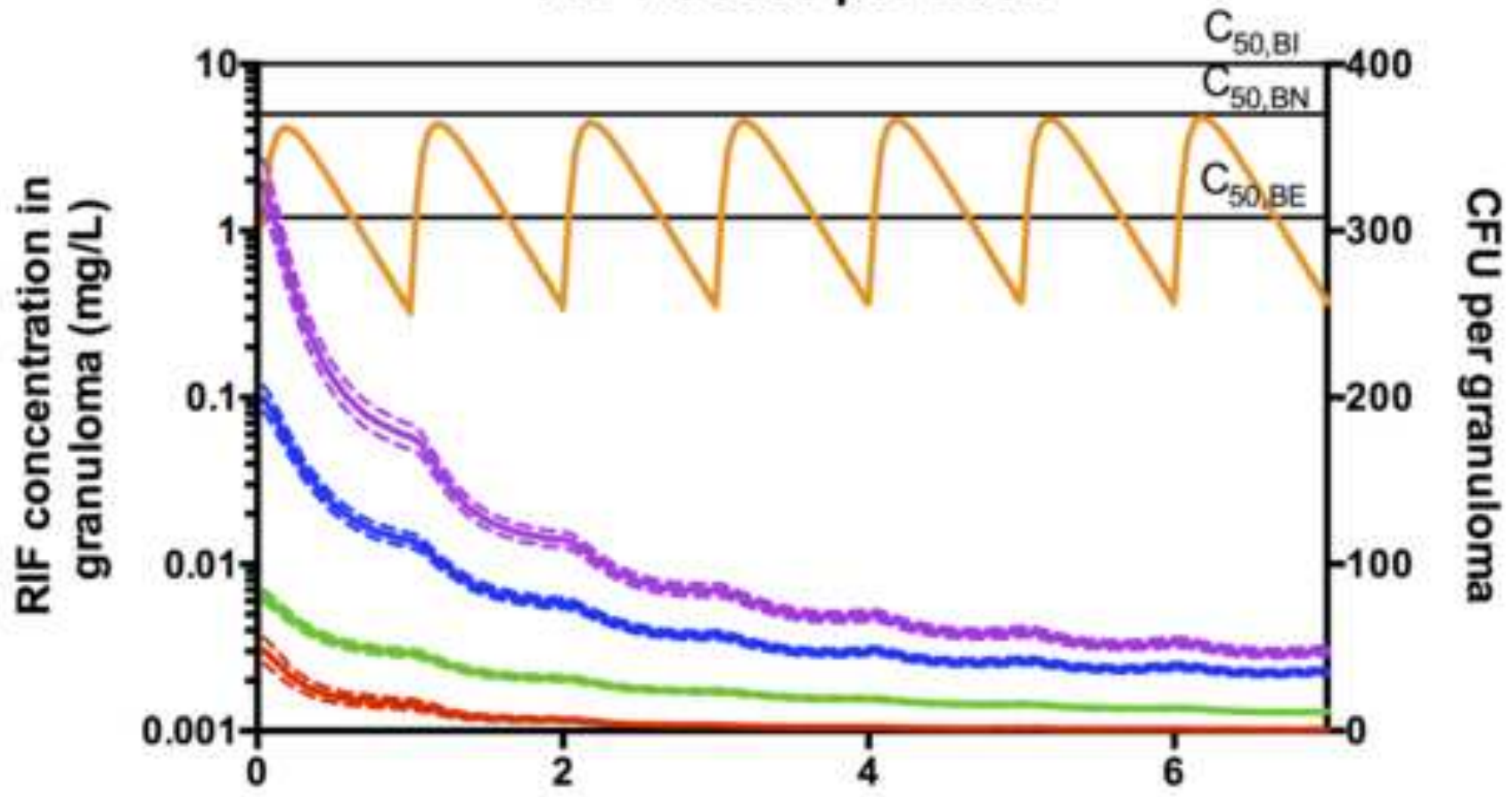

Days post treatment start

$\begin{array}{ll}\text { - Antibiotic concentration in granuloma } & - \text { Replicating Extracellular Mtb } \\ \text { - Total CFU } & - \text { Non-replicating Extracellular Mtb } \\ \text { - Intracellular CFU } & \end{array}$




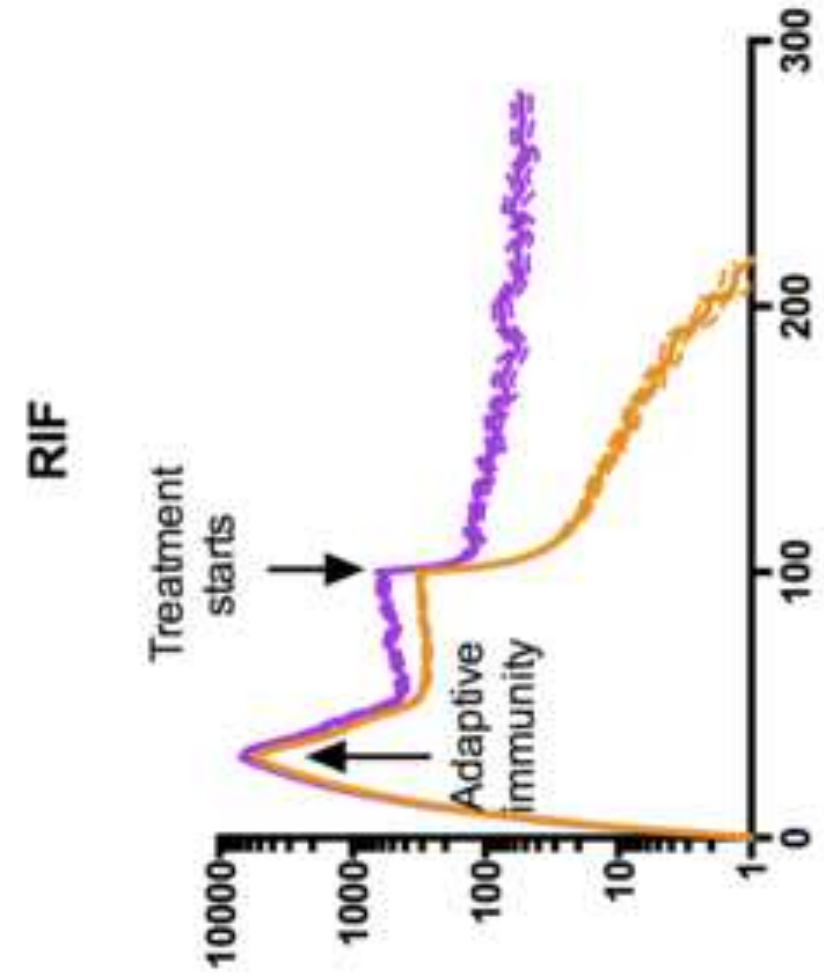

$\boldsymbol{m}$
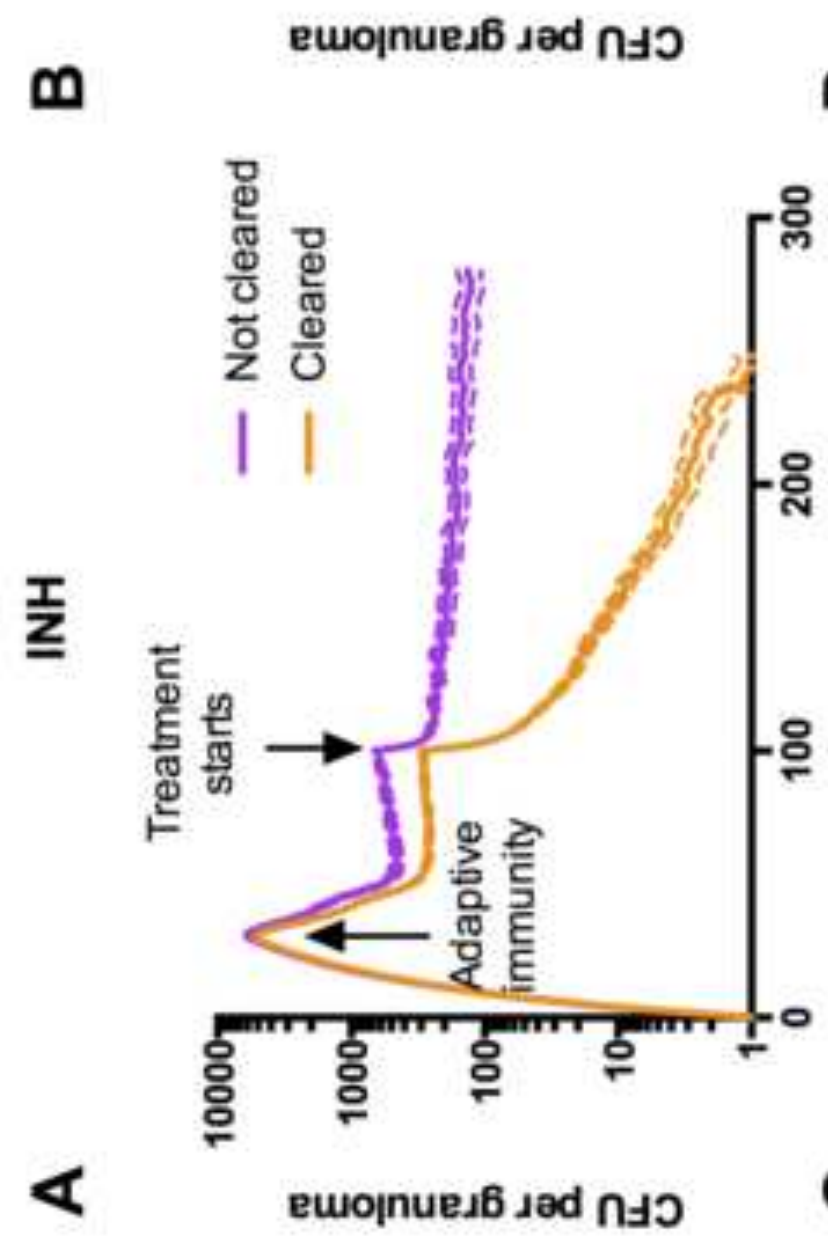

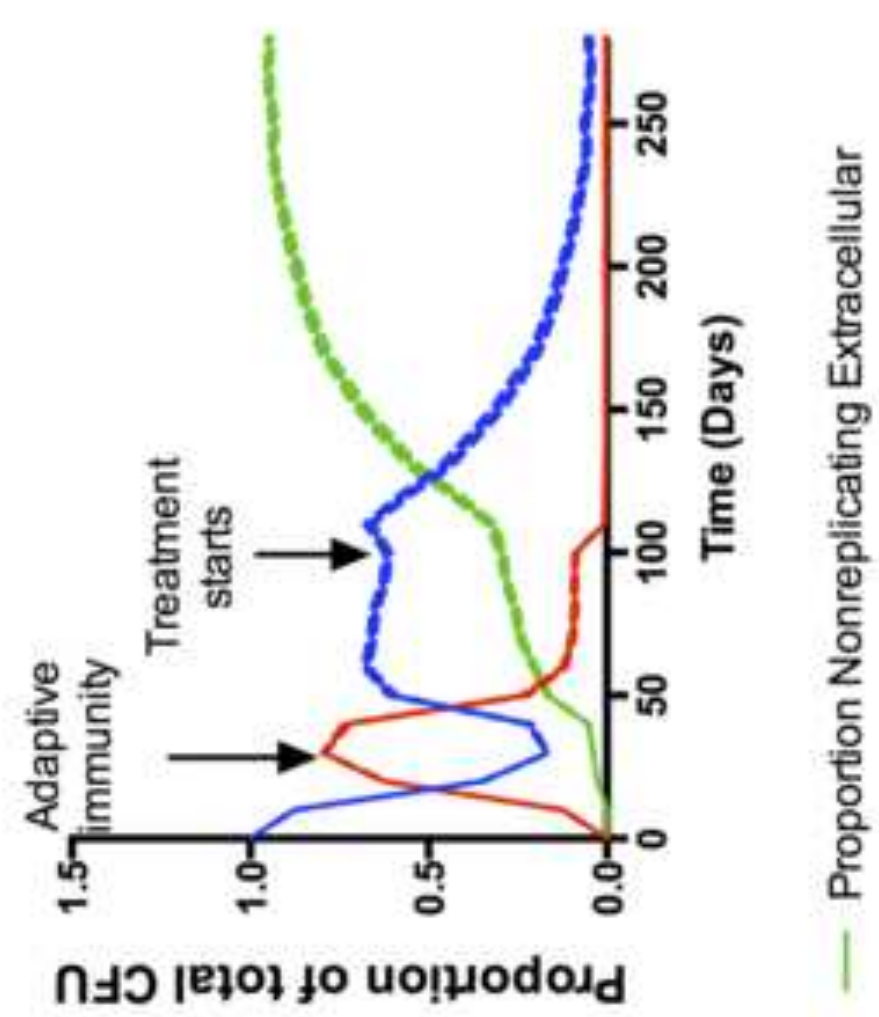

口

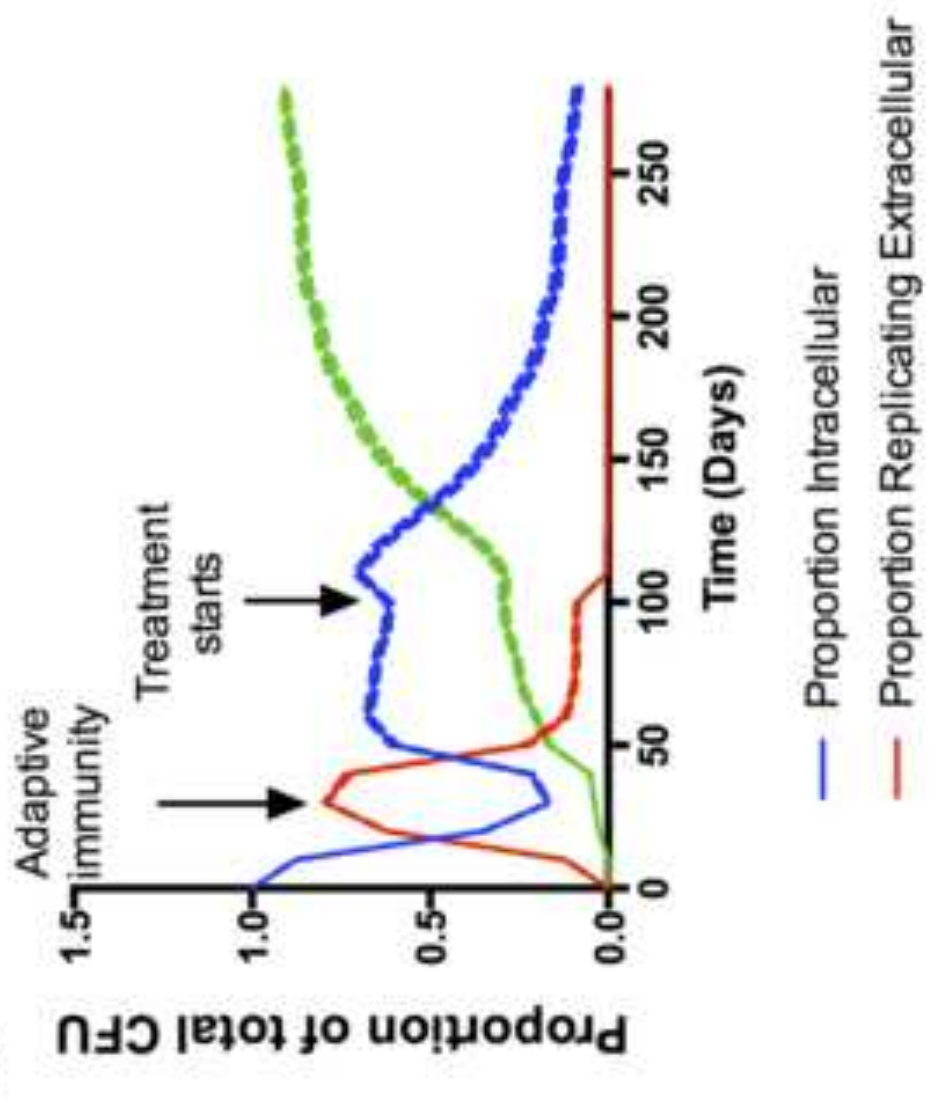



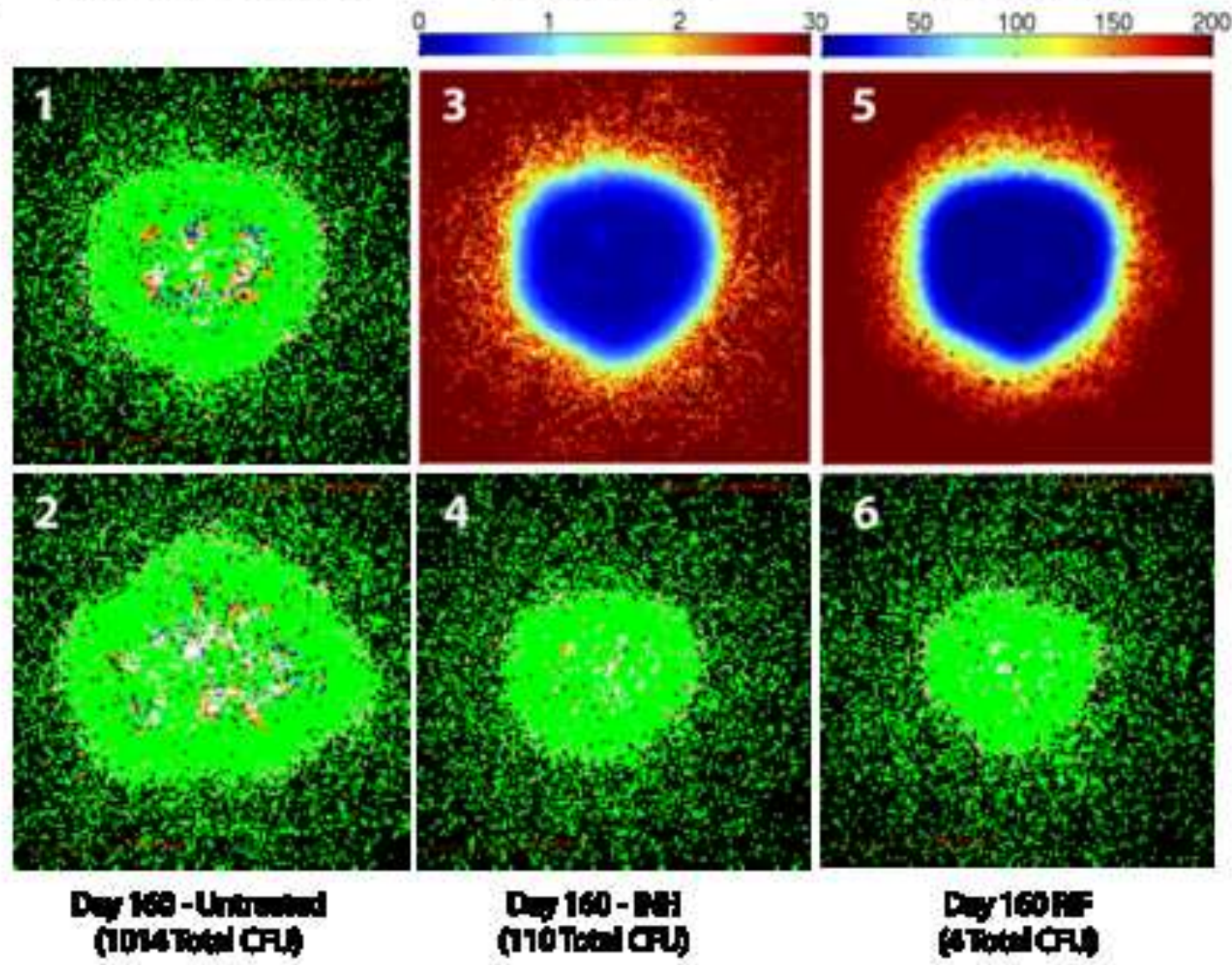

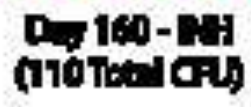

\section{DF160F \\ (s)}

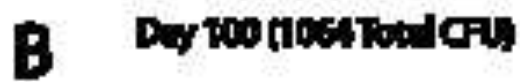

Dor100нан

Dy 1BOFFAC
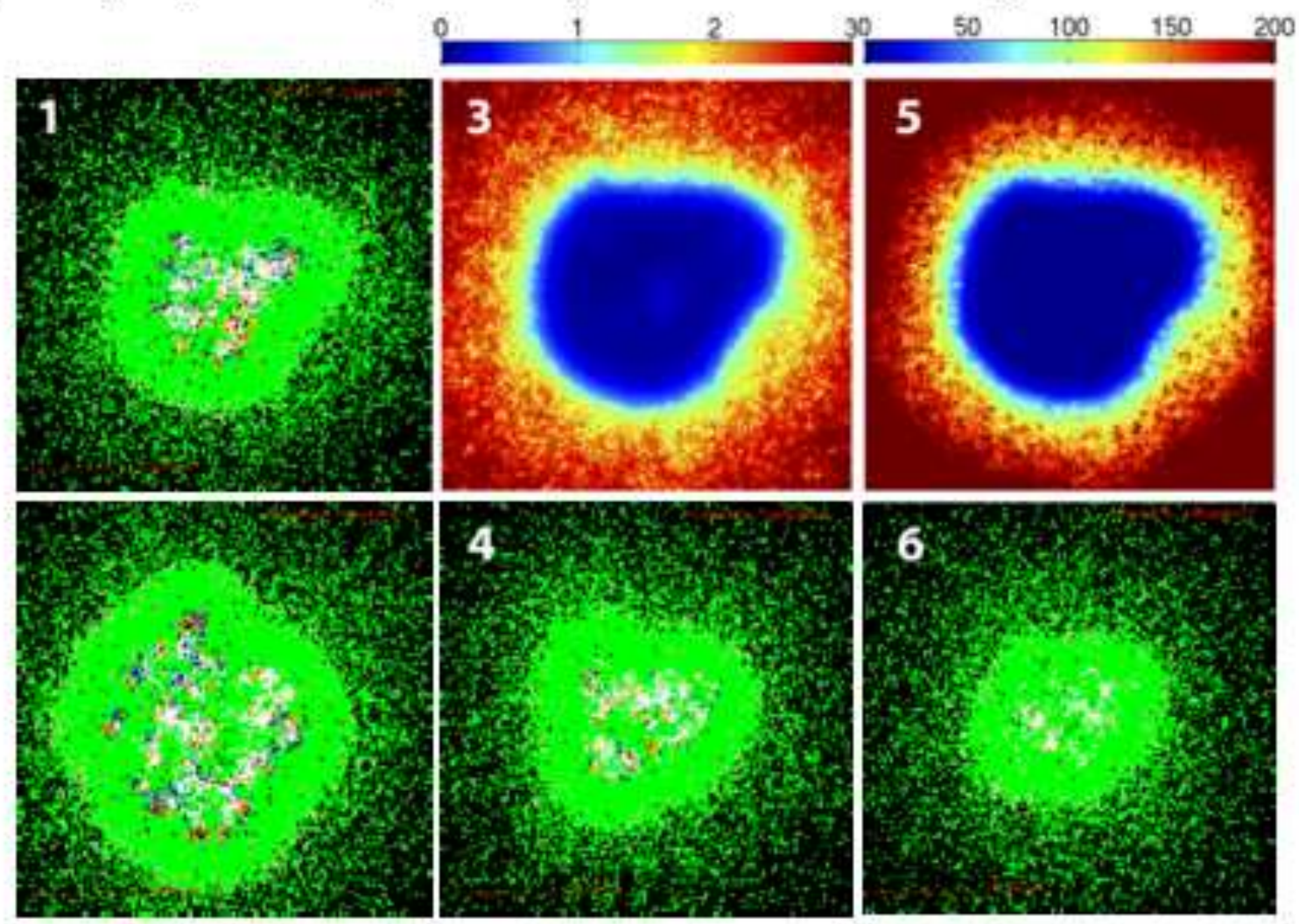

parberis 


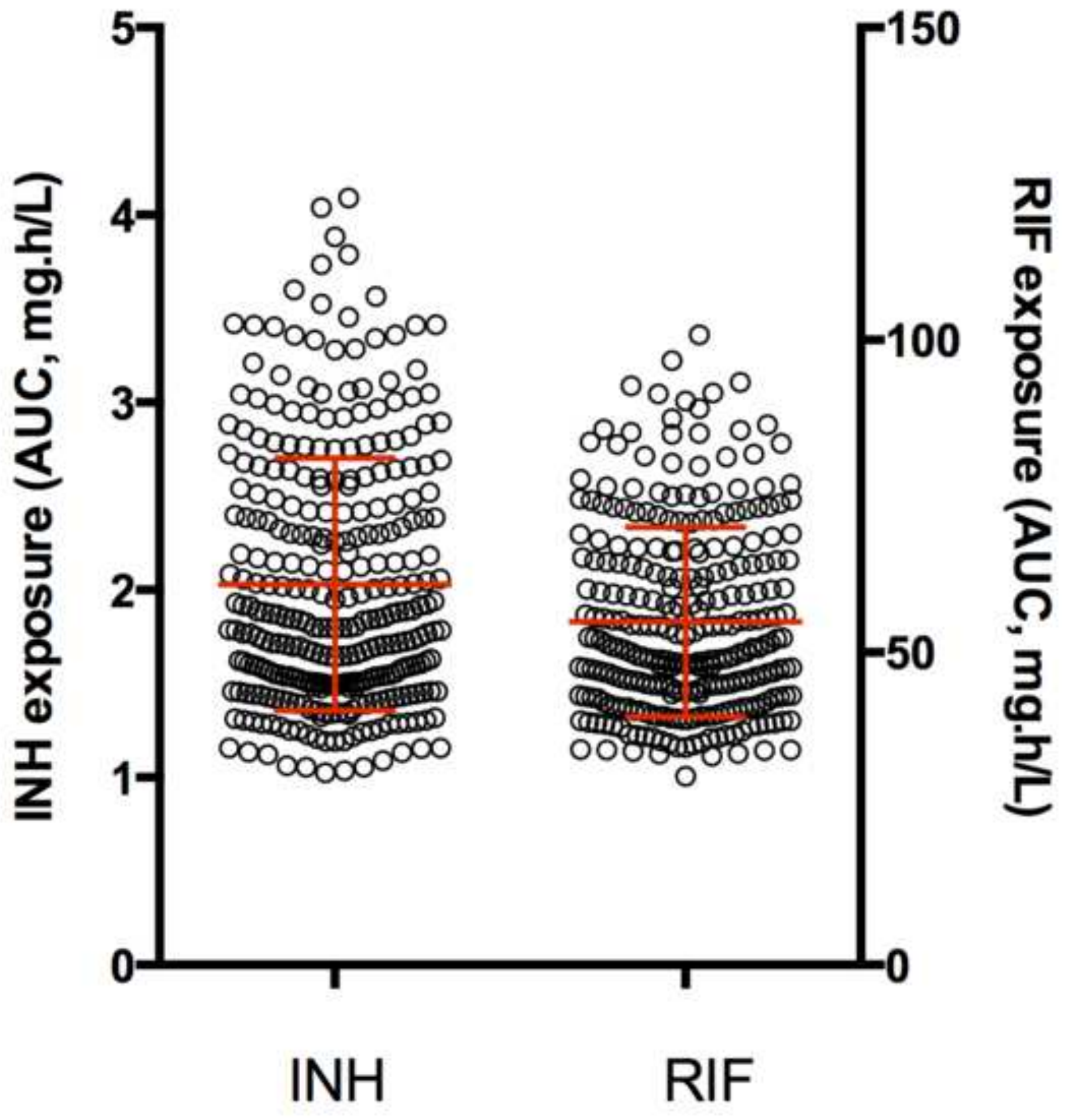

